\title{
High gain CPW-fed UWB planar monopole antenna-based compact uniplanar frequency selective surface for microwave imaging
}

\author{
Raed Abdulkareem Abdulhasan*1,2 ${ }^{\text {| }}$ Azlan Alias ${ }^{1}$ | Khairun Nidzam Ramli ${ }^{1}$ | \\ Fauziahanim Che $\operatorname{Seman}^{1}$ | Raed A. Abd-Alhameed ${ }^{3}$ \\ ${ }^{1}$ Department of Communication Engineering, Faculty of Electrical and Electronic Engineering, Universiti Tun \\ Hussein Onn Malaysia, Batu Pahat, Johor, Malaysia. \\ ${ }^{2}$ Department of Electrical Engineering, Faculty of Engineering, Mustansiriyah University, Baghdad, Iraq. \\ ${ }^{3}$ School of Electrical Engineering and Computer Science, University of Bradford, Bradford, UK.
}

\section{Correspondence}

Raed Abdulkareem Abdulhasan, Department of Communication Engineering, Faculty of Electrical and Electronic Engineering, Universiti Tun Hussein Onn Malaysia, Batu Pahat, Johor, Malaysia.

Email: raadabd39@gmail.com

Running short title: High gain UWB antenna based FSS for MWI

\begin{abstract}
In this article, a novel uniplanar ultra-wideband (UWB) stop frequency selective surface (FSS) was miniaturized to maximize the gain of a compact UWB monopole antenna for microwave imaging applications. The single-plane FSS unit cell size was only $0.095 \lambda \times$ $0.095 \lambda$ for a lower-operating frequency had been introduced, which was miniaturized by combining a square-loop with a cross-dipole on FR4 substrate. The proposed hexagonal antenna was printed on FR4 substrate with coplanar waveguide feed, which was further backed at $21.6 \mathrm{~mm}$ by $3 \times 3$ FSS array. The unit cell was modeled with an equivalent circuit, while the measured characteristics of fabricated FSS array and the antenna prototypes were validated with the simulation outcomes. The FSS displayed transmission magnitude below $10 \mathrm{~dB}$ and linear reflection phase over the bandwidth of 2.6 to $11.1 \mathrm{GHz}$. The proposed antenna prototype achieved excellent gain improvement about $3.5 \mathrm{dBi}$, unidirectional radiation, and bandwidth of 3.8 to $10.6 \mathrm{GHz}$. Exceptional agreements were observed between the simulation and the measured outcomes. Hence, a new UWB baggage scanner system was developed to assess the short distance imaging of simulated small metallic objects in handbag model. The system based on the proposed antenna displayed a higher-resolution image than the antenna without FSS.
\end{abstract}




\section{KEYWORDS}

$\mathrm{CPW}$, detection, FSS, hexagonal patch, microwave imaging, miniaturizing, ultra-wideband antenna

\section{1 | INTRODUCTION}

Variation in the reflection properties of several objects in a conventional handbag appears to be the main motivation of utilizing microwave imaging (MWI) systems to detect hidden metallic object(s) for scanner applications. Non-ionizing radiation, low power level, and low manufacturing cost are some features implemented in the MWI systems, instead of using an X-ray baggage scanner machine.

The ultra-wideband (UWB) imaging system has emerged to be the best candidate due to its broad spectrum that enhances image resolution. UWB antennas are designed with specific traits (broad bandwidth of $3.1-10.6 \mathrm{GHz}$ and high gain) to enhance the construction of images in bag scanner via MWI. As such, a trade-off had been explored between a miniaturized UWB antenna and its low operation frequency. The unidirectional radiation pattern (UDR) antenna is strongly recommended to gain transmitted signals toward the targets, mainly because thescattered signals are observed at an accurate location, which carries the required variation in the features of the detected object(s). Therefore, designing a suitable UWB antenna that presents high performance in meeting all the mentioned requirements is indeed a challenge within the context of MWI application.

UWB patch monopole antennas have been utilized for many MWI applications [1-7]. UDR, high gain, and extensive bandwidth of UWB antenna are required in designing MWI baggage scanner system. The main issue is to obtain UDRs from the UWB planar monopole antenna within theUWB spectrum.

To begin with, a patch monopole antenna [1] was presented with a cavity back to generate UDRs for MWI application. The printed patch monopole antennas [2-5] were presented with metallic reflectors to make the antenna radiate in UDRs. Nonetheless, these reports did not deal with the whole UWB bandwidth, despite the use of high dielectric constant $\left(\varepsilon_{r}=9.8\right)$ [4]. Both the cavity-back and metallic reflector were inefficiently generated UDRs within a broadfrequency range. As a result, the proposed techniques seemed to minimize the antenna bandwidth with poor radiation efficiency due to out-of-phase reflection [6]. In a recent work, an artificial magnetic conductor (AMC) [8] and an electromagnetic band gap (EBG) [9, 10] were applied as reflectors. Both AMC and EBG suppressed the electromagnetic field of the surface wave at the operating frequency. Both EBG and AMC unit cells were not only large 
in size, but also generated a narrow bandwidth and nonlinear phase reflection coefficient $[8$, 10]. Typically, the uniplanar compact photonic-band gap (UC-PBG) band-pass layers were suspended above the antenna patch as lens or aperture to enhance antenna gain [11-13]. Conversely, the multilayer bandstop frequency selective surfaces (FSSs) were proposed to reflect the back radiation of patch monopole antennas [6, 7] for MWI applications. Although multilayer FSSs can reflect radiation in a wide bandwidth, it can increase both design profile and intricacy.

An FSS operation frequency was operated at $\lambda / 2$ of its unit cells electrical length. Demonstrating a finite FSS array size for practical devices by increasing the number of array elements, however, was constricted due to electrical length. Hence, miniaturizing the unit cell size of FSS may exert performances of an infinite array [12].

With that, the primary objective of this study is to design broadband, compact-size, and low-profile FSS array in order to attainUDR and high gain, as well as maintaining the bandwidth of UWB planar monopole antenna. Reflection bandwidth refers to a property of reflecting radiation at a frequency range of 3.1 to $10.6 \mathrm{GHz}$ of $\mathrm{UWB}$ with $\mathrm{S}_{21}<-10 \mathrm{~dB}$. Most UWB FSS reflectors in the cutting-edge literature were reviewed and compared. The general impression of these papers referred to the multilayer stop-band FSSs in achieving UWB reflector[6, 7, 14-20]. Nevertheless, the multilayer had cascade spacing between the FSS layers that can increase the overall design size, the manufacturing cost, the intricacy, the nonlinear phase reflection coefficient, and the multipath reflection at the overlapping frequency between two FSS layers.

In general, the UWB stop FSS offers poor phase matching due to the large propagation phasedelay variation of the reflected radiations at differentfrequencies. Literature pertaining to FSS scarcely depictedthe phase matching between the direct and the reflected signals, particularly for short spacingbetween UWB antenna and FSS layers. Hence, literature concerning UWB FSS reflector using FR4 substrate was assessed. Twolayers of FSSs were proposed in Refs. [14-17] with a nonlinear reflection coefficient phase, while others looked into linear falling reflection coefficient phase in dual-plane FSSs [6, 18, 19], except in Ref. [20], where the reflection coefficient phase was ignored. Furthermore, the proposed UWB FSS in Ref. [7] had four FSS layers. Although multilayer FSSs in the cutting-edge literature have employed to attain UWB reflectors, the reflected radiations of UWB antenna with FSS have not achieved the complete phase matching.

The multilayer FSSs to date reported to attain UWB bandwidth reflection [6, 7, 14-20]. Nonetheless, only a handful of studies had assessed the linear falling reflection coefficient 
phase of FSSs for UDR UWB antenna [6, 18, 19]. In fact, the broad stopband FSS should be relatively large in size due to the low inductive effect and the lower operation bandwidth. The smallest FSS unit cell on FR4 substrate in the literature was reported by Kundu [17] with a size of $0.108 \lambda \times 0.108 \lambda$ to realize the UWB bandwidth reflector with two-layer FSS, where $\lambda$ corresponded to the free space wavelength of the lower operation frequency with a transmission coefficient lower than $-10 \mathrm{~dB}$. To the best of the author's knowledge, a uniplanar compact-size low-cost FSS that led to linear decreasing reflection coefficient phase of UWB stop response has not been reported in the literature.

In this article, a uniplanar UWB FSS was miniaturized to improve the UWB antenna gain for MWI application. The rest of this paper was organized as follows. In Section 2, both copper square-ring and cross-dipole were combined on the top side of FR4 substrate to serve as a broad bandwidth reflector. This compact unit cell gave a reflection performance within the 2.6 to $11.1 \mathrm{GHz}$ range and generated a linear decline of the reflection phase over the entire UWB spectrum. Thus, this study investigated the theoretical operation mechanism and the equivalent circuit of the proposed unit cell. In Section 3, $3 \times 3$ FSS array was formed with UWB patch monopole antenna, successfully generated high-gain and UDR due to the phase matching. In Section 4, the FSS array and the proposed UWB antenna with FSS prototypes were measured and validated with the simulated results from CST Microwave Studio for empirical characterization. In Section 5, a new MWI baggage detection approach was developed based on the proposed UDR monopole antenna. Finally, a conclusion was addressed in Section 6.

\section{2 | THE PROPOSED FSS DESIGN}

\section{1 | FSS design and its operation}

Figure 1a illustrates a 3D view of the FSS array. The metal layer was a combination of a square-ring and a cross-dipole in multiple periodic cells of the array. The symmetrical spacing $(s)$ between the metal unit cells observed a capacitive act $\left(C_{c}\right)$ for each neighbor cell to achieve reflection at a lower frequency with small spacing. The FSS array had a substrate thickness $\left(T_{f s b}\right)$. The UWB stop FSS unit cell geometry, along with several related parameters, is displayed via $2 \mathrm{D}$ top view in Figure $1 \mathrm{~b}$. The physical dimensions of $D_{x}$ and $D_{y}$ of the unit cell are presented in xy plane.

The following process was performed to attain the broad bandwidth of FSS unit cell. First, the copper square-ring was loaded on top of the FR4 substrate. The square-ring reflected radiation at lower frequency with the entire electrical length of $\lambda / 3$ [21]. Second, the width of 
square-ring $(g)$ was increased to obtain a low inductance $\left(L_{S}\right)$ value while the spacing $(s)$ was decreased to attain a high capacitance $\left(C_{c}\right)$ value. Thus, the bandwidth of the unit cell was enhanced. The empty area in the center of the square-ring had small capacitance $\left(C_{S}\right)$ that allowed high frequencies to pass. Third, on the same layer, a copper cross-dipole was printed in the center of the substrate to reflect the radiation at high frequency with dipole electrical length of $\lambda / 2$. Fourth, the cross-dipole length was increased and connected to the square-ring. The cross-dipole decreased the free area in the center of the square-ring, hence generating high parallel inductance $\left(L_{c}\right)$ and higher series capacitors $\left(C_{S}\right)$ values due to the small cross width $\left(W_{f c}\right)$ and the four triangular free areas, respectively. As a result, the FSS bandwidth was substantially enhanced. The complementary structure of the proposed FSS unit cell attained reflection radiation of both lower and higher frequencies over the UWB spectrum. The aforementioned process pointed toward miniaturized unit cell size and enhancement of the bandwidth.

The bottom layer of the unit cell was metal-free. Hence, a small static capacitance $\left(C_{o}\right)$ of the FSS layer was demonstrated. Assuming that the array structure had a size of period unit cells, the capacitor, $C c$, was observed for each cell with the neighboring cells. The affective length of FSS unit cell $\left(L_{f s s}\right)$ in mm was determined by the following:

$$
L_{f s s}=L f s-g+\frac{L f c-W f c}{2} \approx \frac{c}{2 f_{o} \sqrt{\left(\varepsilon_{r}+1\right) / 2}}
$$

Where $c$ stands for velocity of light in free space $\left(3 \times 10^{8} \mathrm{~m} / \mathrm{s}\right), f_{o}$ is resonating ,frequencyand $\varepsilon_{r}$ refers to relative permittivity of the dielectric used.

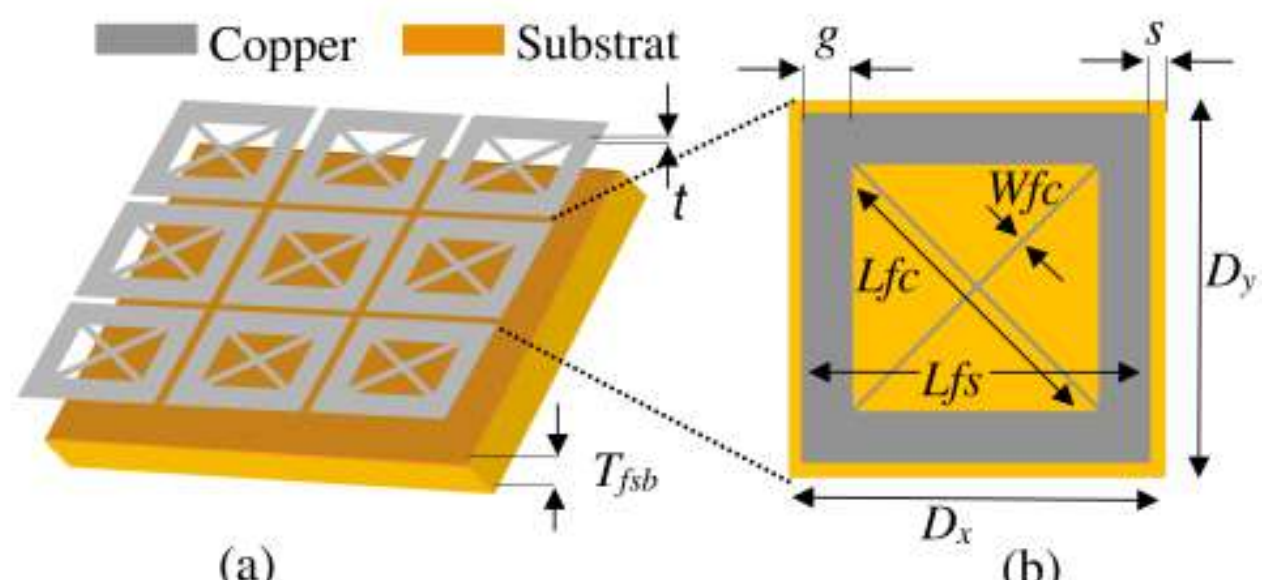

(a)

(b)

FIGURE 1 Geometry of (a) FSS array, and (b) FSS unit cell 


\subsection{FSS equivalent circuit model}

To further comprehend the operation of this FSS unit cell structure, the equivalent circuit model (ECM) is as portrayed in Figure 2. Generally, the ECM of the conventional squarering loop FSS unit cell (band-stop filter) can be modeled as series-shunt inductance $(L)$ and capacitance $(C)$ resonator. The size of the metallic loop was modeled into the FSS inductance, while the spacing on both sides of the metallic element generated the capacitance model due to the neighboring cells [22]. The $L C$ values of the FSS cell were calculated based on size, structure, and substrate materials.

Basically, the self inductance of a metallic stripe was obtained by using the calculation used in Ref. [23] for metallic length and width. The capacitance between any parallel metallic structures was obtained based on the relation between the metallic facing area and the spacing. Both the permittivity in free space $\left(\varepsilon_{o} \approx 8.854 \times 10^{-12} \mathrm{~F} / \mathrm{m}\right)$ and the relative permittivity $\left(\varepsilon_{r}\right)$ of the material between the parallel metallic plates were considered. The substrate of unit cell reflected a sandwich model, as presented by a short length of line transmission (ht) in Figure 2. This transmission line referred to: impedance $Z_{T}=Z_{0} / \sqrt{\varepsilon_{r}}$. Where $Z_{o}=377 \Omega$ is known as wave impedance in free space, while $\varepsilon_{r}$ refers to the relative permittivity of the dielectric substrate. As the substrate was located behind the metallic plane of the model, the impedance $\left(Z_{T}\right)$ was linked in series between the static capacitance, $C_{o}$, of the FSS and $Z_{o}$.

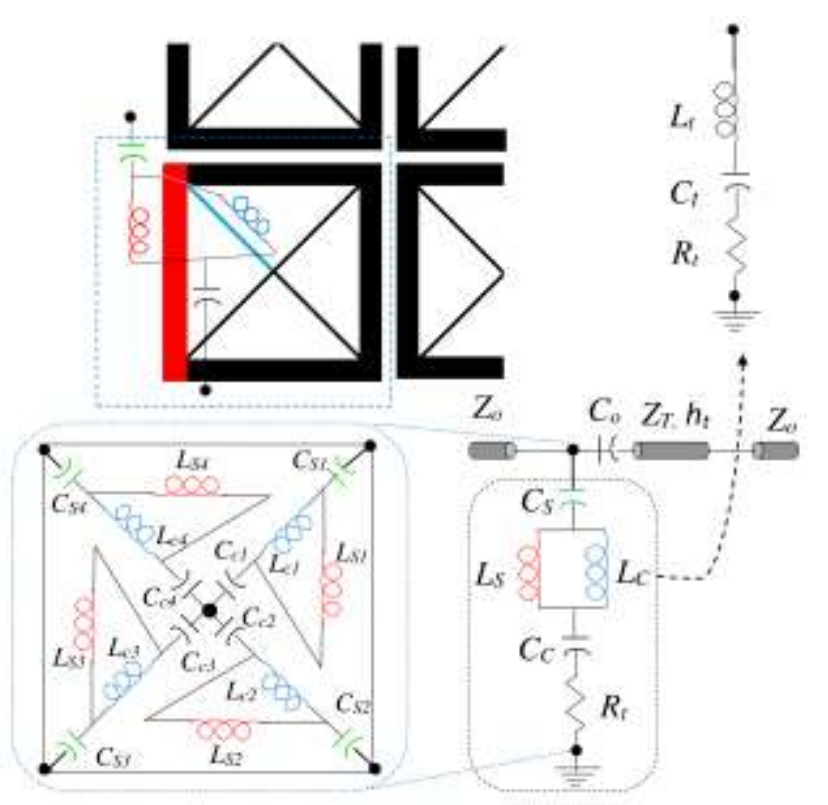

FIGURE 2 FSS equivalent circuit model 
This study proposed the connection between the square-ring loop FSS and cross-dipole FSS on a single-layer unit cell without any ground plane. The explored capacitance, $C_{S}$, between the adjacent FSS cells can be disregarded to simplify the calculation of the whole model. However, in this design, $C_{S}$ was weighed in due to its effect on reflection bandwidth. In order to increase the reflection bandwidth with slightly altering the center frequency, the spacing between the metal of the neighboring unit cells $(2 \times s)$ was reduced. This capacitance was derived based on the proposed unit cell parameters, as given in Equation (2):

$$
C_{S} \approx \varepsilon_{o} \varepsilon_{r} \frac{L_{f s} \times t}{2 s}
$$

The square-ring generated a broad reflection bandwidth. Therefore, inductive $L_{S}$ was derived based on the square-ring parameters, as presented in Equation (3):

$$
L_{S} \approx 2 L_{f s} \times \ln \left(\frac{2 L_{f s}}{g+t}+0.5+\frac{g+t}{3 L_{f s}}\right)
$$

The additional self inductance, $L_{C}$, of the cross metal was connected parallel to $L_{S}$, which shifted the upper edge of the reflection bandwidth to a higher frequency. The cross metal divided the inner area into four small parts. The spacing between the cross and the square was represented by series capacitance, $C_{C}$. Based on the unit cell parameters, $L_{C}$ and $C_{C}$ of the analyzed ECM were determined via Equations (4) and (5), respectively:

$$
\begin{aligned}
& L_{C} \approx 2 L_{f c} \times \ln \left(\frac{2 L_{f c}}{W_{f c}+t}+0.5+\frac{W_{f c}+t}{3 L_{f c}}\right) \\
& C_{C} \approx \varepsilon_{o} \varepsilon_{r} \frac{\left(L_{f s}-2 g\right) \times t}{\left(L_{f s}-2 g\right) / 2}
\end{aligned}
$$

To simplify the proposed ECM, the total inductor, $L_{t}$, was derived from the parallel inductors, $L_{S}$ and $L_{C}$. The total capacitor, $C_{t}$, was incorporated from the series capacitors, $C_{S}$ and $C_{C}$, to obtain resonance frequency and broad bandwidth, while the FSS static capacitor, $C_{o}$, was controlled to attain the bandstop filter bandwidth. The total resistance, $R_{t}$, of the unit cell was connected in series to both $L_{t}$ and $C_{t}$, which managed the transmission magnitude in $\mathrm{dB}$ due to substrate losses and cell resistance. The simplified $R L C$ circuit gave the total impedance, $Z_{f s s}$, of the proposed unit cell, as given in Equation (6):

$$
Z_{f s s}=R_{t}+j \frac{\omega^{2} L_{t} C_{t}-1}{\omega C_{t}}
$$

After simplifying Equation (6), the ECM resonance frequency was obtained using Equation (7) as follows: 


$$
f_{r}=\frac{1}{2 \pi \sqrt{L_{t} C_{t}}}=\left(\frac{1}{2 \pi}\right) \sqrt{\frac{\left(L_{S}+L_{C}\right) \times\left(C_{S}+C_{C}\right)}{L_{S} L_{C} C_{S} C_{C}}}
$$

The insertion loss of $R L C$ circuit exhibited a broad bandstop characteristic after calculating the bandwidth, $B W$, using Equation (8), as reflected in the following:

$$
B W \approx R_{t} / L_{t} C_{o}
$$

\section{3 | FSS simulation and results}

The unit cell was printed on a square FR4 substrate with dielectric constant $\left(\varepsilon_{r}\right)$ of 4.3 , loss tangent $(\tan \delta)$ of 0.025 , thickness $T_{f s b}$ of $1.6 \mathrm{~mm}$, and area $D_{y} \times D_{x}$ of $11 \times 11 \mathrm{~mm}^{2}$. The proposed copper structure had a height $(t)$ of $0.035 \mathrm{~mm}$ printed on the top layer of the substrate. The compact uniplanar unit cell was designed without any ground plane for the bottom layer of the substrate. The copper square-ring had a side length, $L_{f s}$, of $10.8 \mathrm{~mm}$; a width, $g$, of $1.6 \mathrm{~mm}$; and spacing substrate edge, $s$, of $0.1 \mathrm{~mm}$. The cross-dipole parameters were as follows: the length of arms, $L_{f c}=10.6 \mathrm{~mm}$, and the width of arms, $W_{c f}=0.3 \mathrm{~mm}$, as illustrated in Figure 1b.

The electromagnetic characteristics of the unit cell were obtained from CST Microwave Studio, as shown in Figure 3a. Both the simulated transmission and the reflection coefficients are portrayed in Figure $3 b$ by using normal incidence. As a result, the tested FSS unit cell displayed broad bandstop performance. The transmission coefficient exhibited a magnitude below $-10 \mathrm{~dB}$ for the range between 2.6 and $11.1 \mathrm{GHz}$, which was realized with a unit cell size of $0.095 \lambda \times 0.095 \lambda$. The transmission coefficient achieved center stop frequency at6.5 $\mathrm{GHz}$ by simulating the proposed unit cell.

Figure $3 \mathrm{~b}$ displays the reflection coefficient phase $\left(\mathrm{S}_{11} \emptyset_{F S S}\right)$ in degree of the FSS. The $\mathrm{S}_{11}$ $\emptyset_{F S S}$ linearly decreased with increment in the frequency over the whole UWB spectrum. Typically, the reflected radiation delay of $2 \pi$, which was compatible with the direct antenna radiation phase, was realized by generating a stable $S_{11} \emptyset_{F S S}$ curve slope. This condition was satisfied at a constant distance, $D z$, of $\leq \lambda_{0} / 4$ between wideband antenna and FSS array, where $\lambda_{o}$ refers to a wavelength of zero reflection phase shift.

The S-parameters of the proposed ECM wascomputed by using the schematic circuit of CST software to validate both the simulated design and the proposed circuit. Both calculation and optimization processes were performed to determine the $R L C$ values that met similar resonance frequency and bandwidth of the stop band. The ECM parameters had optimum values, as follows: $L_{S}=2.8 \mathrm{nH}, L_{C}=8.6 \mathrm{nH}, C_{S}=8.1 \mathrm{pF}, C_{C}=0.295 \mathrm{pF}, C_{o}=0.085 \mathrm{pF}$, and 
$R_{t}=1.2 \Omega$. The schematic of CST software portrayed a significant agreement between the ECM and the unit cell outcomes, as presented in Figure $3 b$.

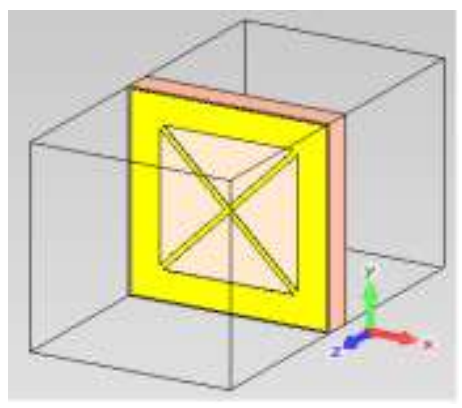

) $\mathrm{a}($

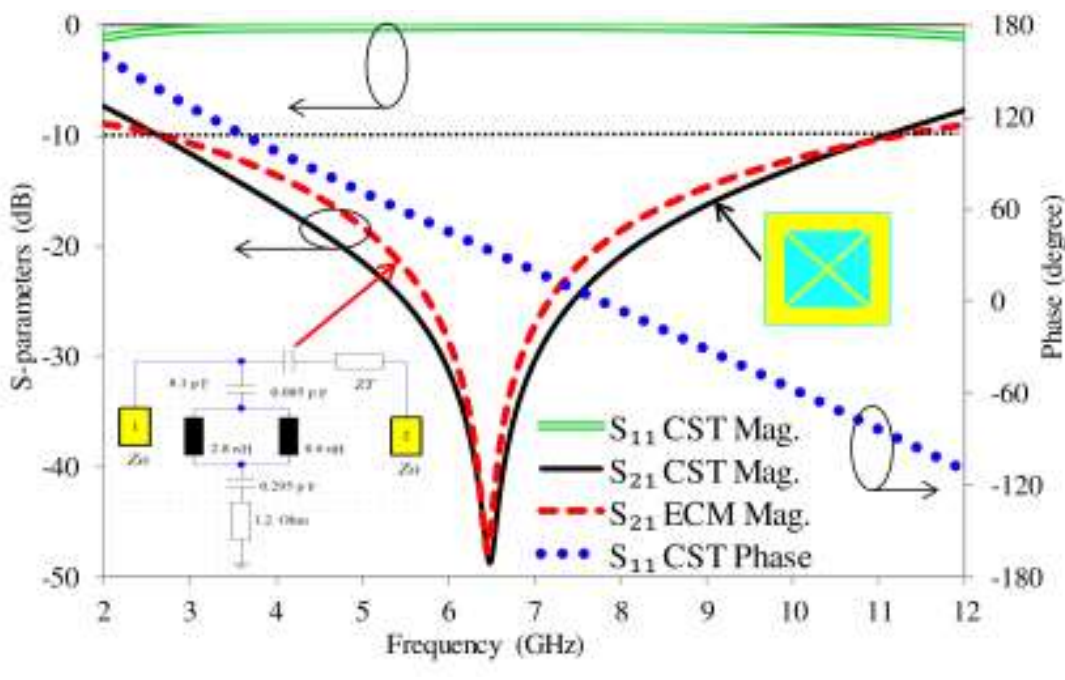

(b)

FIGURE 3 (a) Diagram of the simulation model (b) simulated transmission and reflection coefficients

The simulated outputs highlighted two main points. The first point is that the unit cell parameters were tuned to produce broad reflection bandwidth. The second point is that the center resonance frequency of the unit cell was assessed. Based on Equation (7), reducing the total unit cell size can shift the center reflection to a higher frequency. As such, alarge unit cell size was required to realize reflection at low resonance frequency, which appeared to be a challenge amongst researchers. The use of high dielectric constant substrate can address this issue, as given in Equation(1). Nonetheless, this study had been limited tolow-cost manufacturing using FR4 substrate. The $S_{11} \emptyset_{F S S}$ displayed a linear decreasing slope $(\Delta \mathrm{Ph} / \Delta \mathrm{F})$ of $-27^{\circ} / \mathrm{GHz}$. The antenna gain can significantly improve for the UWB spectrum due to the obtained linear $S_{11} \emptyset_{F S S}$. The negative slope of $S_{11} \emptyset_{F S S}$ approximately equalized the positive slope of pathdelay phase for the broad bandwidth.

The current distribution on the metallic surface was simulated at varied frequencies to determine the reflection mechanism of the proposed FSS structure. A high current flow was observed onboth the square and cross shape at a low frequency of $4.0 \mathrm{GHz}$, as illustrated in Figure 4, while current highly flowed on the cross-shape at a high frequency of $8.0 \mathrm{GHz}$ due to the electrical length. 


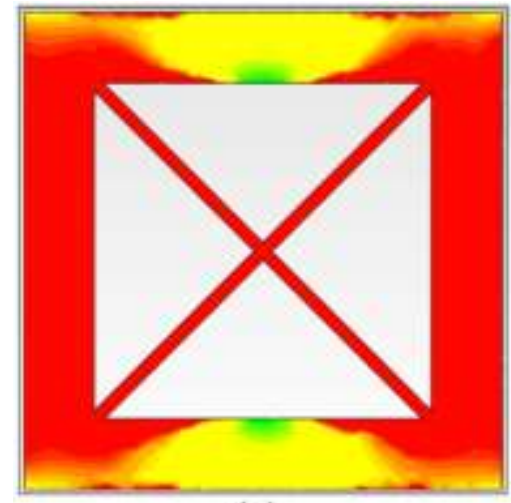

(a)

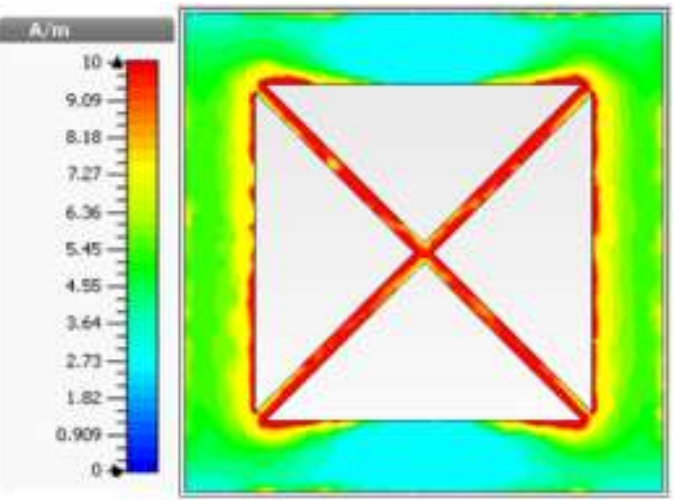

(b)

FIGURE 4 Current distribution on FSS unit cell at (a) $4.0 \mathrm{GHz}$, and (b) $8.0 \mathrm{GHz}$

\section{3 | FORMING UWB MONOPOLE ANTENNA WITH FSS REFLECTOR}

The FSS design delineated in Section 2 was applied to improve the performance of monopole antenna at UWB spectrum. The geometry and the characteristics proposed hexagonal UWB monopole antenna, as comprehensively discussed in Ref. [24]. Figure 5a portrays the parameters of the uniplanar hexagonal patch monopole antenna with coplanar waveguide (CPW) feed (Antenna \#1). The antenna printed on FR4 substrate shared similar thickness $(H)$ and properties of the FSS substrate. To design the antenna with CPW-fed, two copper ground planes were adjusted on the sides of the feed line by a distance of $(S c p w)$. The CPW-fed parameters were analyzed and optimized to achieve $50 \Omega$ impedance of the feed line. The hexagonal patch was modified to enhance the antenna bandwidth. The hexagonal patch parameters were as follows: a short side $\left(S_{1}\right)$, long side $\left(S_{2}\right)$, radius $(R)$, and angle $\left(a^{\circ}\right)$, as depicted in Figure 5a. The values of UWB antenna parameters are tabulated in Table 1. Lower band-edge $\left(f_{L}\right)$ of the proposed antenna was calculated by equating area of the planar antennaand an equivalent cylindrical monopole antenna, as given in Equation(10) [25]. The equivalent cylindrical parameters of the proposed hexagonal patch with unequal angles and sides length were derived, as given in Equation (9):

$$
\begin{gathered}
R=\frac{S_{1}}{[2 \times \sin (a)]}, \quad L=2 \times R, \text { and } r=\frac{\left[2 \times R \times \sin (a) \times \cos ^{3}(a)\right]}{\pi} \\
f_{L}=\frac{c}{\lambda}=\frac{7.2}{[(L+r+p) \times k]} \mathrm{GHz}
\end{gathered}
$$

where $L$ is the height of the planar monopole antenna in $\mathrm{cm}, r(\mathrm{~cm})$ refers to the effective radius of equivalent cylindrical monopole antenna, $p$ represents the probe length, and $k=1.15$ 
reflects the constant for FR4 substrate. The hexagonal patch monopole antenna was selected to operate in front of the FSS array reflector.
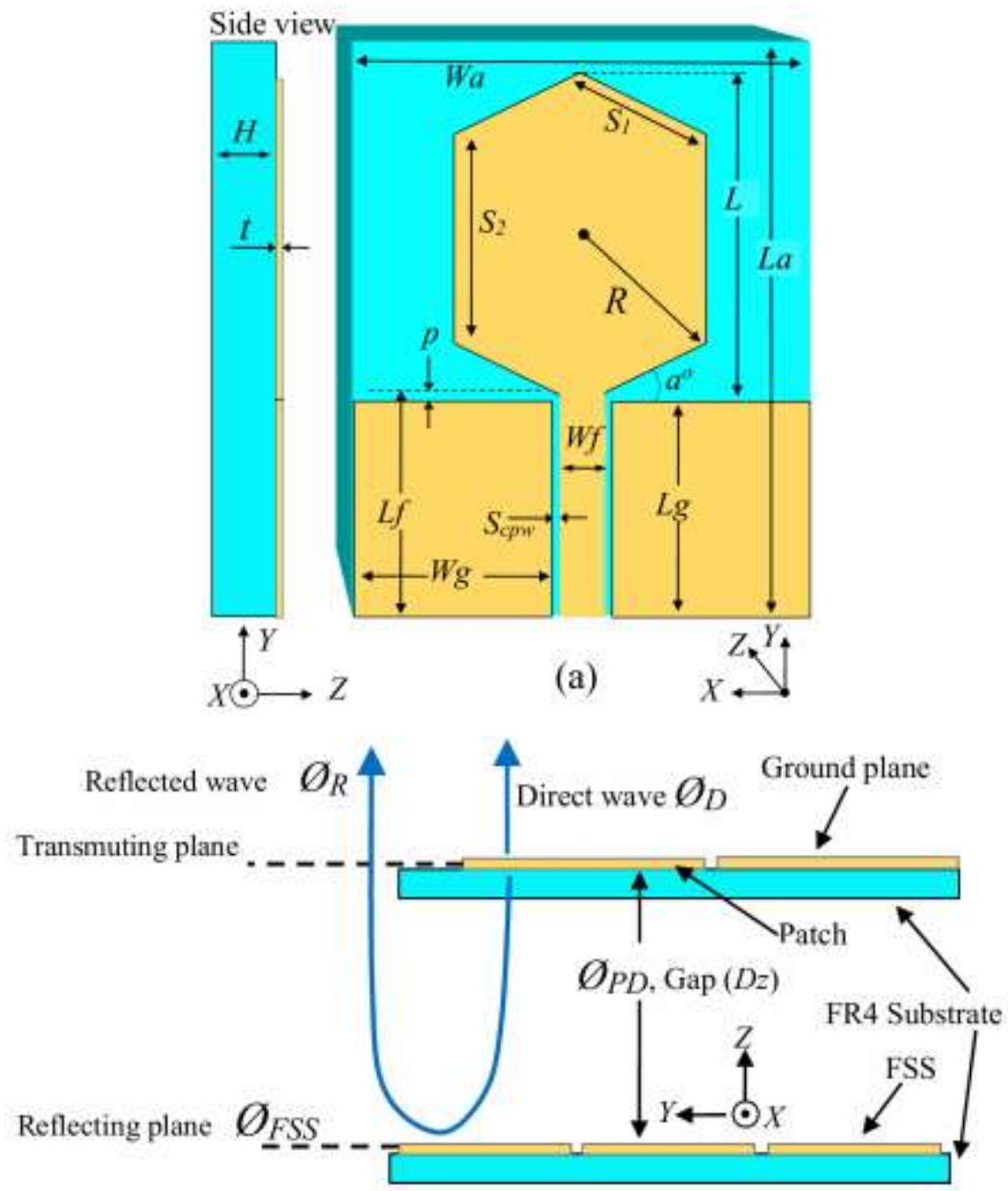

(b)

FIGURE 5 (a) Antenna \#1 parameters on 3D and side views, and (b) side view of Antenna \#2 TABLE 1. The parameters of the proposed hexagonal patch monopole antenna

\begin{tabular}{|l|l|l|l|}
\hline Parameter & Value $(\mathrm{mm})$ & Parameter & Value $(\mathrm{mm})$ \\
\hline$S_{1}$ & 8.5 & $S c p w$ & 0.27 \\
\hline$S_{2}$ & 11 & $W g$ & 14.3 \\
\hline$t$ & 0.035 & $L g$ & 11.1 \\
\hline$W f$ & 2.5 & $W a$ & 31.9 \\
\hline$L f$ & 11.4 & $L a$ & 30 \\
\hline$p$ & 0.4 & $H$ & 1.6 \\
\hline$a^{\circ}$ & $24^{\circ}$ & $R$ & 10.45 \\
\hline
\end{tabular}


In this study, a numerical method was employed to determine the distance $(D z)$ between the antenna and the proposed FSS reflector. Based on the antenna size, $3 \times 3$ unit cells were organized in a single-layer rectangular array FSS. Figure 5b illustrates Antenna \#1 that was formed with the FSS array printed on the FR4 substrate with $D z$ spacing. The distance, $D z$, was calculated carefully to enhance the antenna gain by reflecting the back radiation. Therefore, a parametric study of Antenna\# 2with FSS array at different spacing $D z$ can illustrate the performance enhancement.

The simulated reflection coefficients of Antenna \#2 were studied at the different distances of $D z$ as shown in Figure 6a. From the simulation study, both gain and bandwidth of Antenna \#2 were investigated by varying the spacing $D z$ between the FSS array and the antenna. Figure $6 \mathrm{~b}$ portrays the variation of $\mathrm{Dz}$ in $\mathrm{x}$-axis from 14.6 to $29.6 \mathrm{~mm}$. Lower frequency $(F l)$ and higher frequency $(F h)$ of the antenna resonance bandwidth $\left(\mathrm{S}_{11}<-10 \mathrm{~dB}\right)$, peak gain at $F l$, and peak gain at $F h$ of the antenna were represented in y-axis. The resonance bandwidth $(F l=3.2 \mathrm{GHz}$ to $F h=12.5 \mathrm{GHz})$ was significantly improve at $D z=21.6 \mathrm{~mm}$, but decreased at other $D z$ values. Moreover, the maximum peak gain of $F h$ was realized at $8 \mathrm{dBi}$ and 21.6 $\mathrm{mm}$ spacing, while the peak gain of $F l$ smoothly dropped from 7.0 to $3.4 \mathrm{dBi}$ by increasing the $D z$ from 14.6 to $29.6 \mathrm{~mm}$. A trade-off was noted between the peak gain at $F l$ and the peak gain at $F h$ after varying the spacing, $D z$. This was attributable to the phase matching between the front and the reflected signals at a particular frequency. The antenna gain can be improved when the reflected signals have a phase of $(n \times 2 \pi)$ to the front signals.

The phase shift of Antenna \#2 was further analyzed at $D z=21.6 \mathrm{~mm}$ due to the maximum operation bandwidth and optimum gain enhancement. The total phase shift of the reflected signal was calculated by considering the path delay phase $\left(\emptyset_{P D}\right)$ and the FSS phase $\left(\emptyset_{F S S}\right)$, as given in Equation (11). $\emptyset_{P D}$ mainly relied on distance, $D z$, and a particular frequency calculated using Equation (12). The normal incidence was considered, in which the incident wave was perpendicular to the FSS layer (incident angle, $\theta=0^{\circ}$ ) and air gap, $\varepsilon_{r}=1$, the numerical calculation of $D z=21.6 \mathrm{~mm}$ led to $\emptyset_{P D}=2 \pi$ at $6 \mathrm{GHz}$ (see Figure $6 \mathrm{c}$ ). The proposed FSS gave a linear falling of $\emptyset_{F S S}$, which approximately equalized the linear increase of $\emptyset_{P D}$ over the UWB spectrum. The simulated reflection coefficient phase $\left(S_{11} \varnothing\right)$ unwrapped of both the proposed FSS unit cells and the UWB antenna were imported into the workspace. The UWB back radiation was successfully reflected with FSS array. 


$$
\begin{aligned}
& \phi_{R}(f)=2 \phi_{T, \mathrm{Ant}}(f)-\phi_{P D}(f)-\phi_{F S S}(f)=\phi_{D}(f)+2 n \pi \\
& \text { where } \quad n= \pm 1, \pm 2, \pm 3, \ldots \\
& \phi_{P D}(f)=2 \beta \times D z \times \sqrt{\varepsilon_{r}-\sin ^{2}(\theta)}, \quad \beta=\frac{2 \pi}{\lambda}
\end{aligned}
$$

where $\emptyset_{R}$ is the phase of reflected wave, $\emptyset_{D}$ is the phase of direct wave (see Figure $5 \mathrm{~b}$ ), $\varnothing_{T}$ is the transmission phase of the antenna, $f$ is the operating frequency, $\lambda$ is the wavelength, $\beta$ is the propagation constant of free space, $\theta$ is the incident angle, $\varepsilon_{r}$ is the dielectric constant of spacing (air), and $D z$ is the spacing distance.

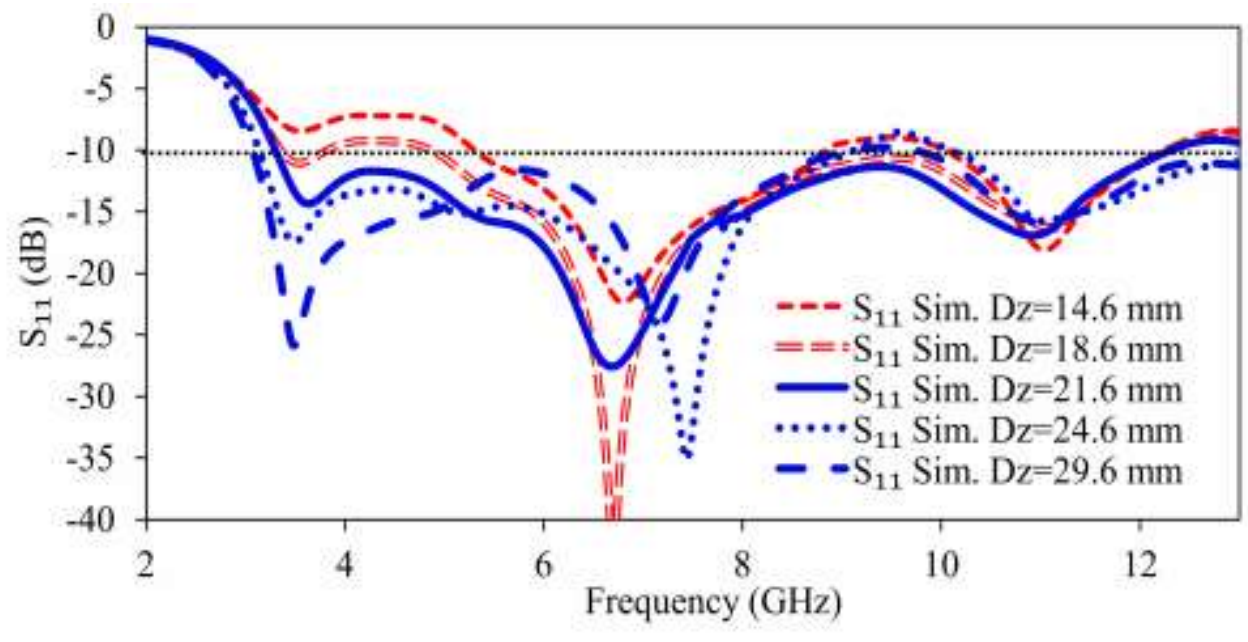

(a)

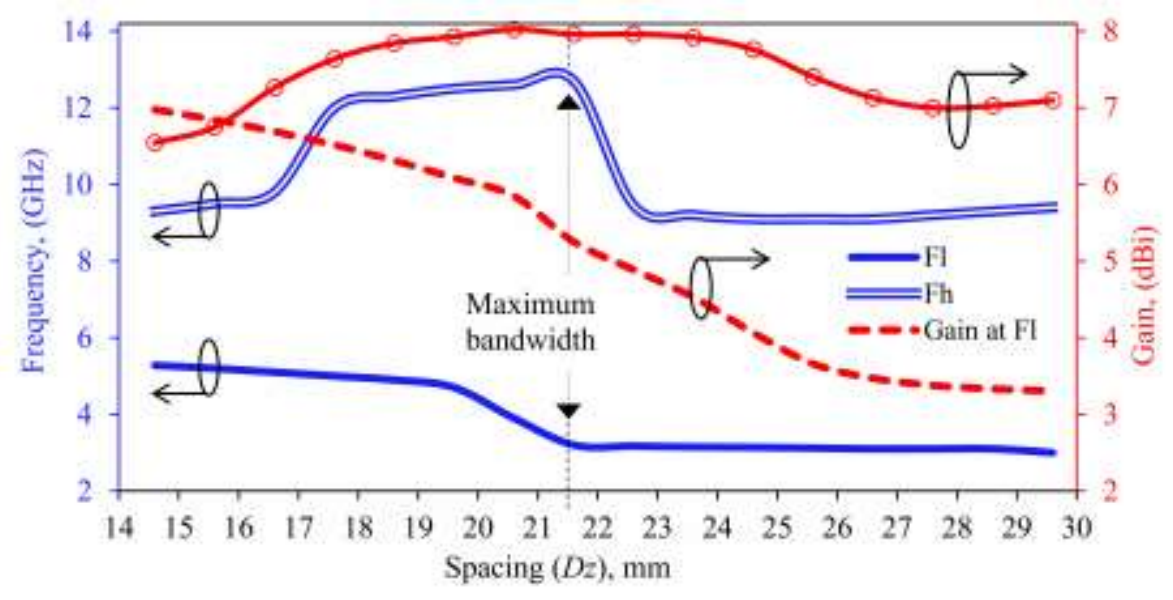

(b) 


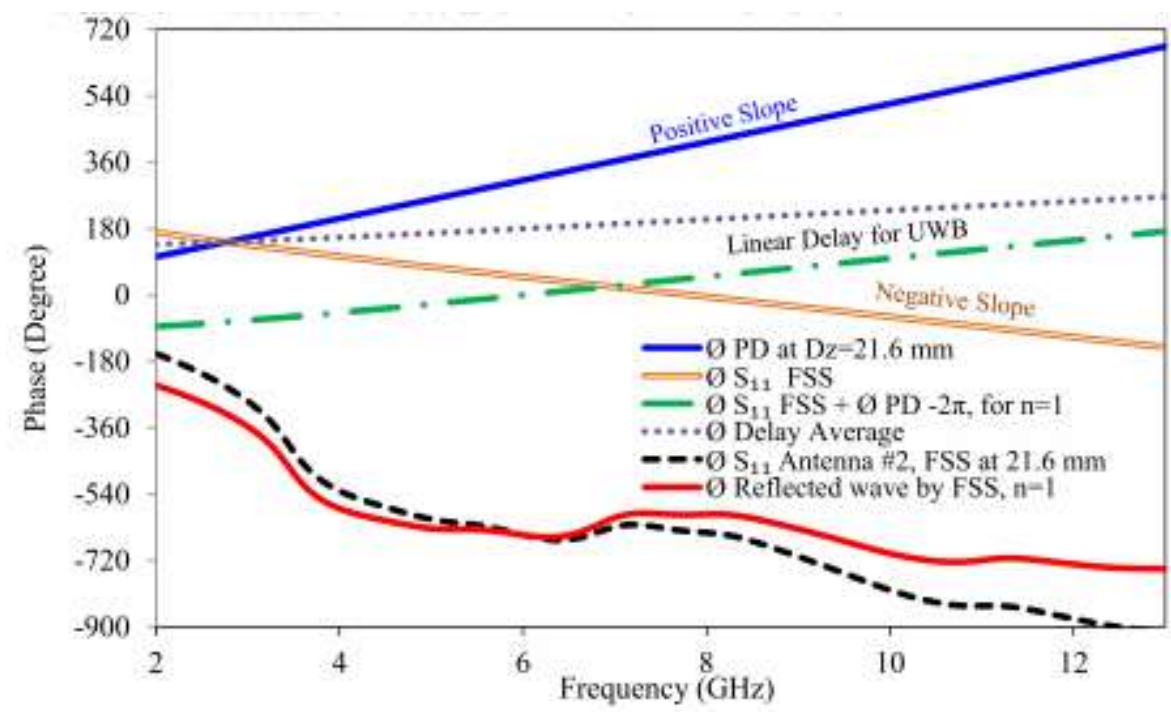

(c)

FIGURE 6 Simulated variation of Antenna \#2 reflection coefficients in (a), study of antenna bandwidth and gain in (b) at the different distances of $D z$, and (c) the transmitted and reflected (reflected wave) unwrap Antenna \#2 phases

Based on the mathematical calculation in Equations (11) and (12), the reflected signal obtained a phase of the moving path $\emptyset_{P D}$ of $(2 \times \beta \times D z)$ sum with $\emptyset_{F S S}$. The summation results of the Equation (11) parameters are portrayed in Figure 6c. The sum phase vector had a delay of $(1 \times 2 \pi)$ due to the moving path $\emptyset_{P D}$. The final outcomes are presented in Figure $6 \mathrm{c}$ by setting $n=1$ and $D z=21.6 \mathrm{~mm}$, which displayed exceptional agreement between the antenna phase shift and the reflected signal phase. In brief, the proposed FSS array demonstrated $1 \times 2 \pi$ phase shift between the direct and the reflected signals at $6 \mathrm{GHz}$ when $D z=21.6 \mathrm{~mm}$.

The reflected signal phase was compatible with the direct signal phase for the entire UWB spectrum. Thus, the antenna gain and the bandwidth were improved by simulating the complementary design at $D z=21.6 \mathrm{~mm}$. Next, Figure 7 illustrates the simulated antenna gain and return loss (magnitude) of both with and without FSS array. The antenna gain sharply improved (from 4.8 to $7.8 \mathrm{dBi}$ ) for all UWB spectra with the proposed FSS array. The antenna gain could be further enhanced by increasing the number of cells for the FSS array. 


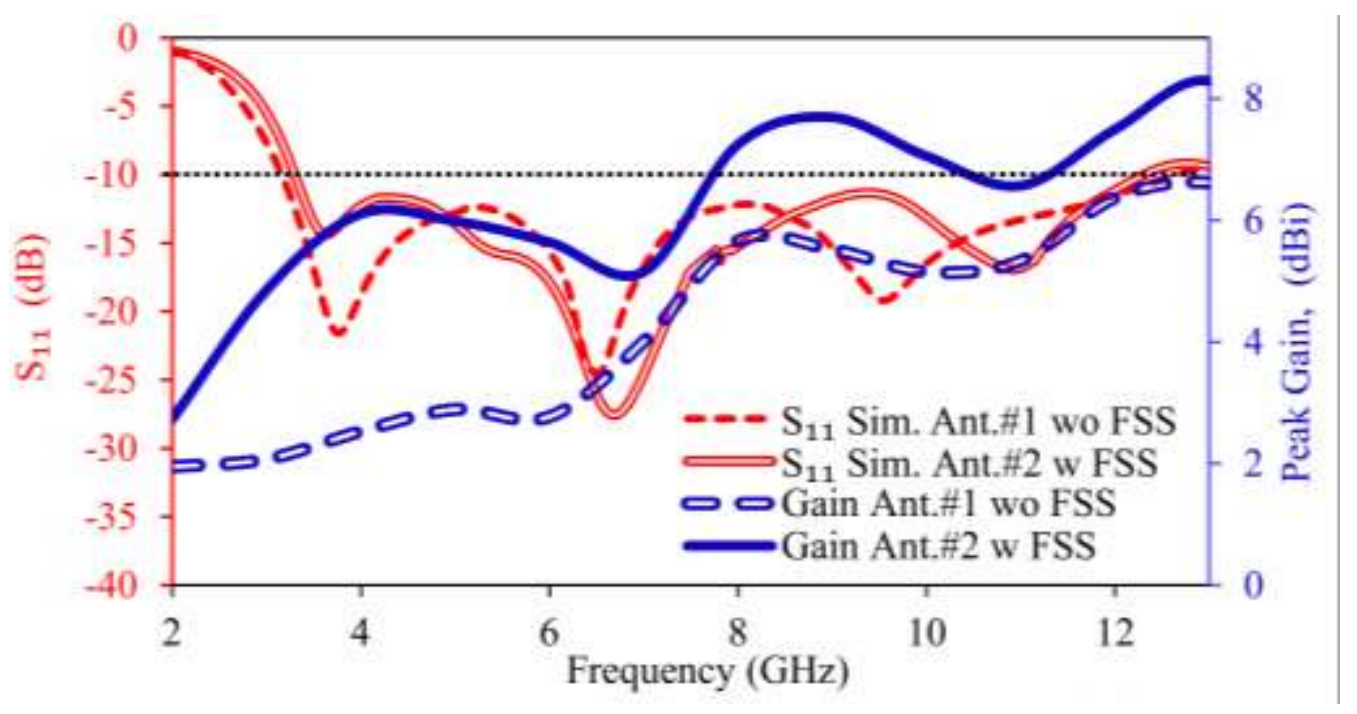

FIGURE 7 Validation of simulation for Antennas \#1 and \#2 return loss and peak gain

\section{PROTOTYPES FABRICATION AND MEASUREMENT RESULTS}

\section{1 | Experimental results of FSS array}

For further validation, a prototype of the single-layer FSS array was fabricated on FR4 substrate. Figure 8a shows the FSS array prototype with $54 \times 36$ elements, whereas Figure $8 \mathrm{~b}$ presents the zoom view of the FSS unit cells prototype. Two opposite horn-antennas were applied to measure the transmission coefficients of the fabricated prototype. The bi-static free space measurement was performed by connecting two horn-antennas to B\&S ZVB14 Vector Network Analyzer [26]. Initially, the calibration was carried out for the fixed antennas above absorber with a spacing of $100 \mathrm{~cm}$ between them. After that, the measured transmission coefficient was normalized without incorporating the FSS array. Next, the FSS array was placed between the antennas, as shown in Figure 8c. Subsequently, two adjacent horns were placed at a distance of $50 \mathrm{~cm}$ from a copper plate, which has a size as same as the FSS array to calibrate a reference $S_{11}$. Then, the reflection coefficient was normalized by incorporating the copper plate. The reflection coefficient was measured by placing the FSS array, instead of the copper plate, as shown in Figure 8d. The normal incidence was weighed in to determine the transmission coefficient of the transverse electric wave. The measured $S_{21}$ and $S_{11}$ magnitude were recorded from the network analyzer.

Both the simulated and measured S-parameters of fabricated FSS prototype, as shown in Figure 8e, displayed good agreement between the measurement and simulation outcomes. Interestingly, the measured stop bandwidth ranged between 3.2 and $11.3 \mathrm{GHz}$, while the minimum transmission magnitude was $-41 \mathrm{~dB}$ at $7.0 \mathrm{GHz}$. The ripples of the results were 
polished by using the smooth average option, which were generated from coaxial cables and connections losses. The FSS prototype was printed on the lossy substrate by using the conventional process. The center frequency of the measured transmission coefficients was shifted slightly to a higher frequency due to fabrication tolerance, in comparison to simulation outcomes.

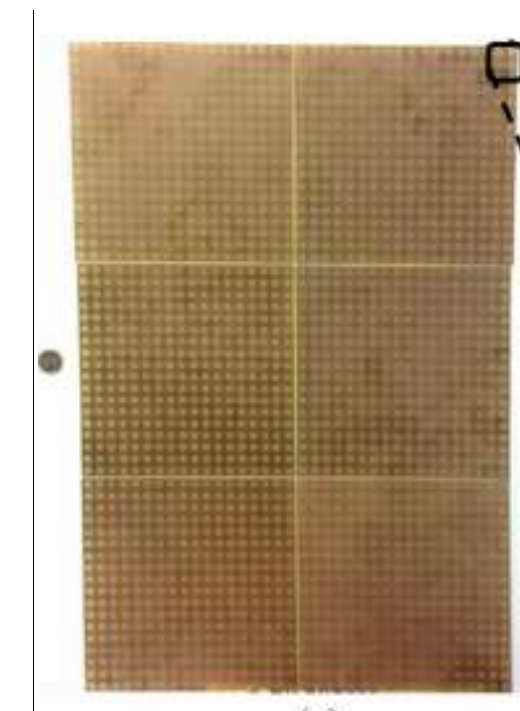

(a)

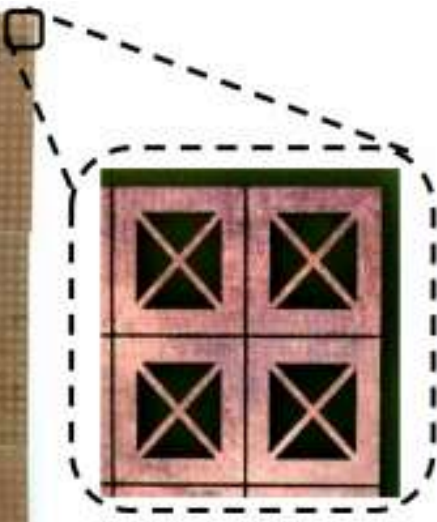

(b)

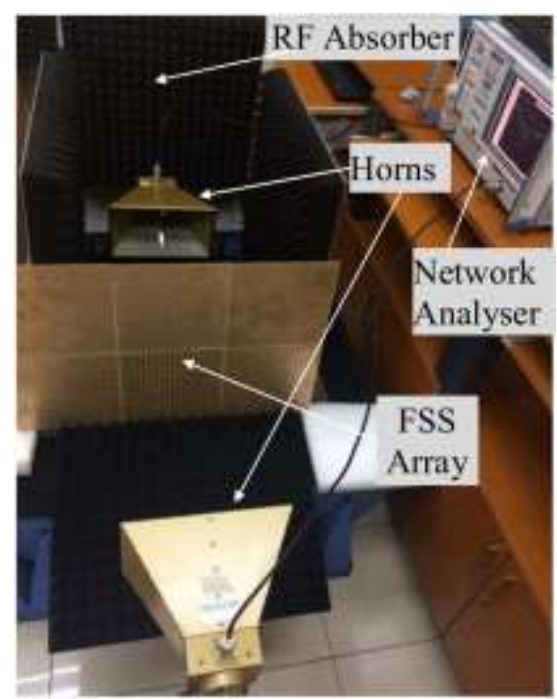

(c)

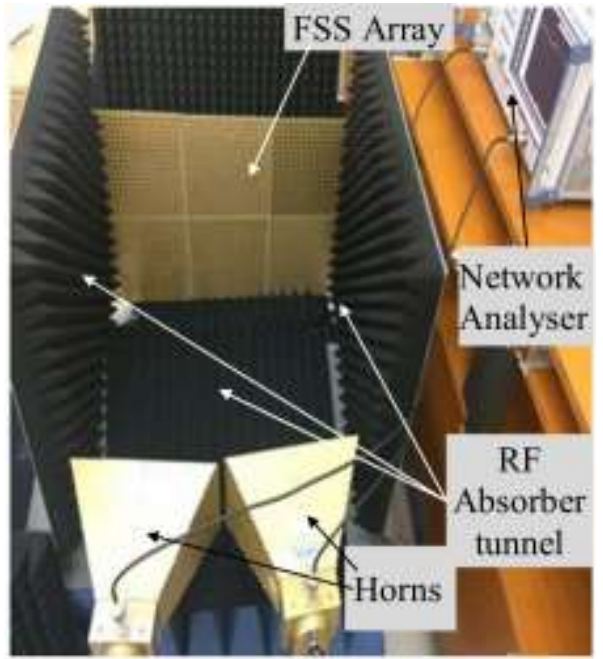

(d)

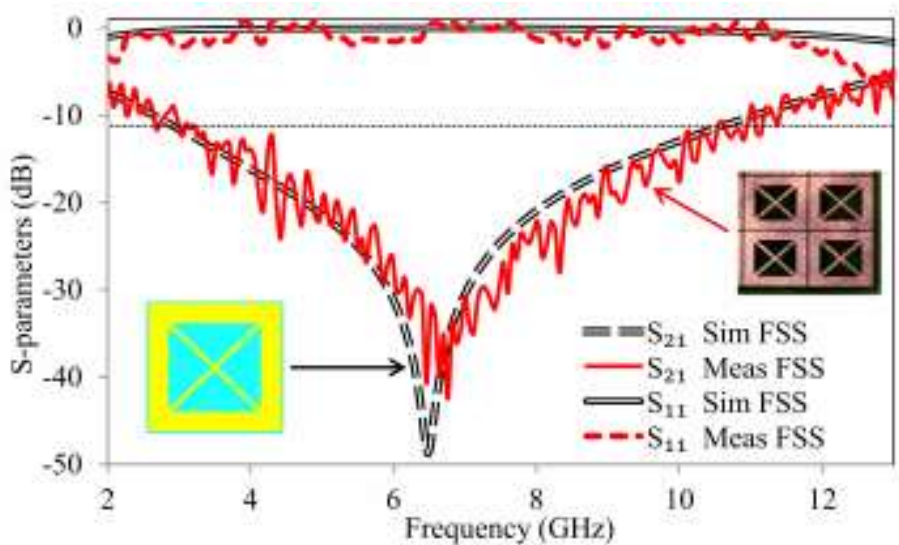

(e)

FIGURE 8 (a) Photograph of the FSS array prototype $54 \times 36$ elements, (b) zoom-in view of

the unit cells, (c) bi-static $S_{21}$ measurement, (d) bi-static $S_{11}$ measurement of FSS array prototype, and (e) simulated and measured S-parameters magnitude of FSS

\subsection{Experimental results of UWB antenna-based uniplanar FSS reflector}

The characteristics of fabricated hexagonal monopole antenna were determined and validated with the simulation outcomes for both Antenna \#1 without FSS and Antenna \#2 
with FSS reflector. Figures 9a,b portray the images of Antennas \#1 and \#2 with $3 \times 3$ FSS array prototypes, respectively. To hold the design structure during measurement, the substrates of the antenna and the FSS array were increased by $10 \mathrm{~mm}$ at both left and right sides. This aided in combining the antenna with FSS via spacers. The air spacing distance, $D z$, was maintained by using Teflon spacers between the monopole antenna and the FSS array. The size of the proposed design (Antenna \#2) was only $30 \times 31.9 \times 21.6 \mathrm{~mm}^{3}$.

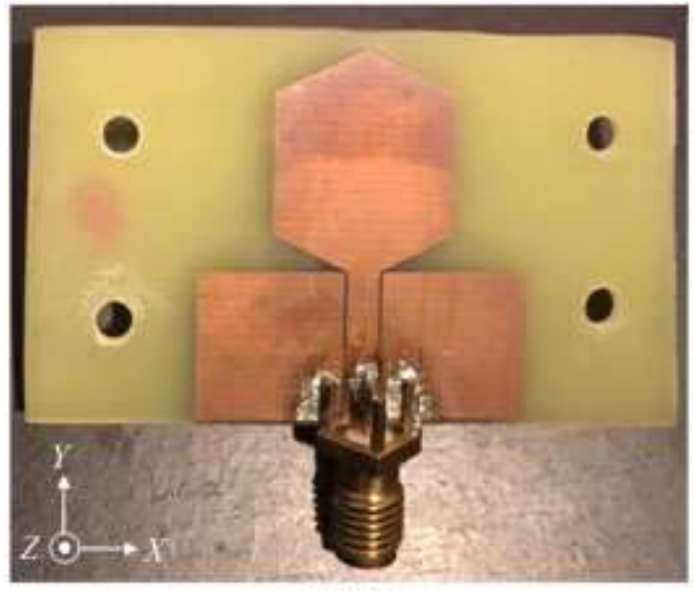

(a)

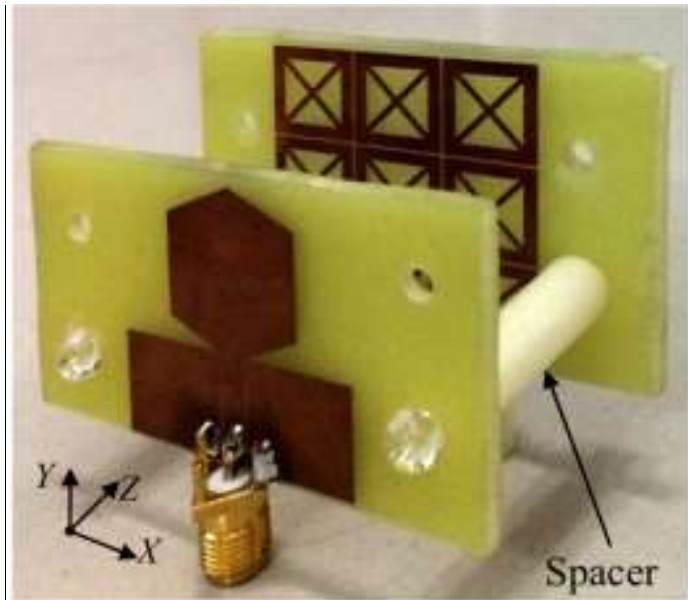

(b)

FIGURE 9 Prototypes of (a) Antenna \#1, and (b) Antenna \#2

The $\mathrm{S}_{11}$ magnitudes of Antennas \#1 and \#2 were measured with B\&S ZVB14 Vector Network Analyzer. The comparison between the simulated and the measured $S_{11}$ magnitudes is presented in Figure 10 to propose hexagonal Antennas \#1 and \#2. As a result, good agreement was achieved between the simulated and the measured $S_{11}$ for both antennas. Antenna \#1 displayed the operation bandwidth ranging from 3.4 until $10.7 \mathrm{GHz}$, while the bandwidth of Antenna \#2 reduced slightly within the range from 3.8 until $10.6 \mathrm{GHz}$. The antenna bandwidth decreased at lower and higher edges due to the phase matching. The $S_{11}$ magnitude of Antenna \#2 enhanced at $6 \mathrm{GHz}$ due to the phase matching of both the direct and the reflected radiation. This slight variation between the simulated and measured outcomes had been due to fabrication inaccuracies, Teflon spacers, and SMA connector losses (matching range between $\mathrm{DC}$ and $12 \mathrm{GHz}$ ). 


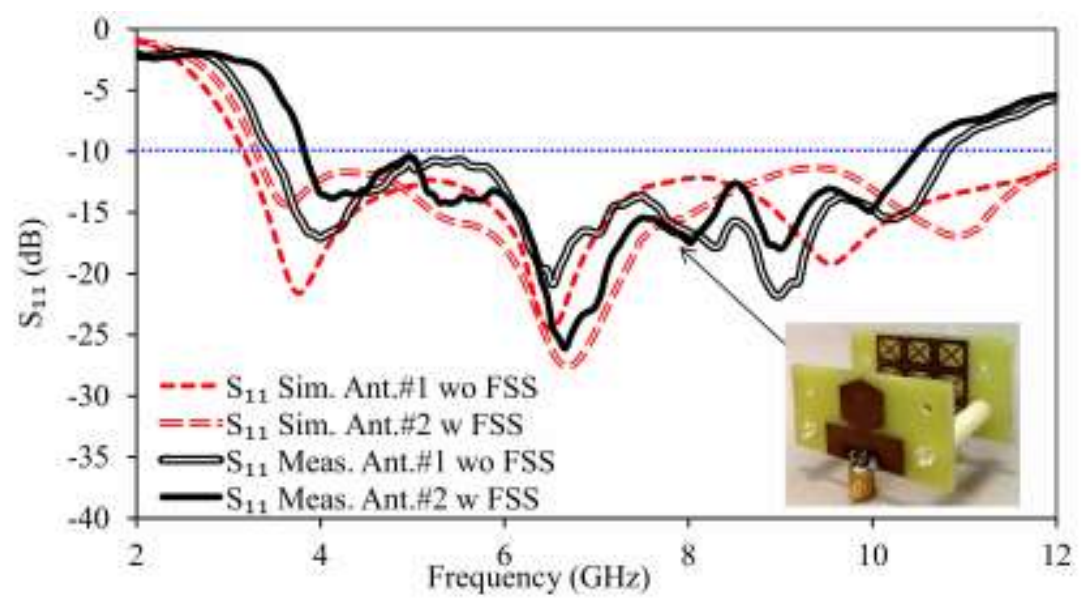

FIGURE $10 \mathrm{~S}_{11}$ measurement and simulation of Antenna \#1 and Antenna \#2

Next, the performances of Antennas \#1 and \#2 were compared to verify the improvement brought by the proposed FSS reflector. Figure 11 illustrates the simulation and measurement peak gains of Antennas \#1 and \#2. The measured gain for Antenna \#1 changed from 1 to 6 $\mathrm{dBi}$ at measurement spectrum. Likewise, Antenna \#2 resulted in high measured gain values from 2 to $8 \mathrm{dBi}$. The simulation gain of Antenna \#2 that improved by $3.8 \mathrm{dBi}$; higher than that for Antenna \#1 over UWB spectrum. Hence, the measured gain of Antenna \#2 enhanced by about $3.5 \mathrm{dBi}$ by using only $3 \times 3 \mathrm{FSS}$ array at $21.6 \mathrm{~mm}$ spacing. As such, higher gain of Antenna \#2 can be obtained by increasing the number of the unit cells (such as $5 \times 5$ or $7 \times 7$ ) for the FSS array (including increment in design size). Reducing the spacing distance, $D z$, also increased antenna gain, but decreased the bandwidth. Thus, embedding the proposed FSS array behind the monopole antenna can substantially enhance the gain at the broad bandwidth.

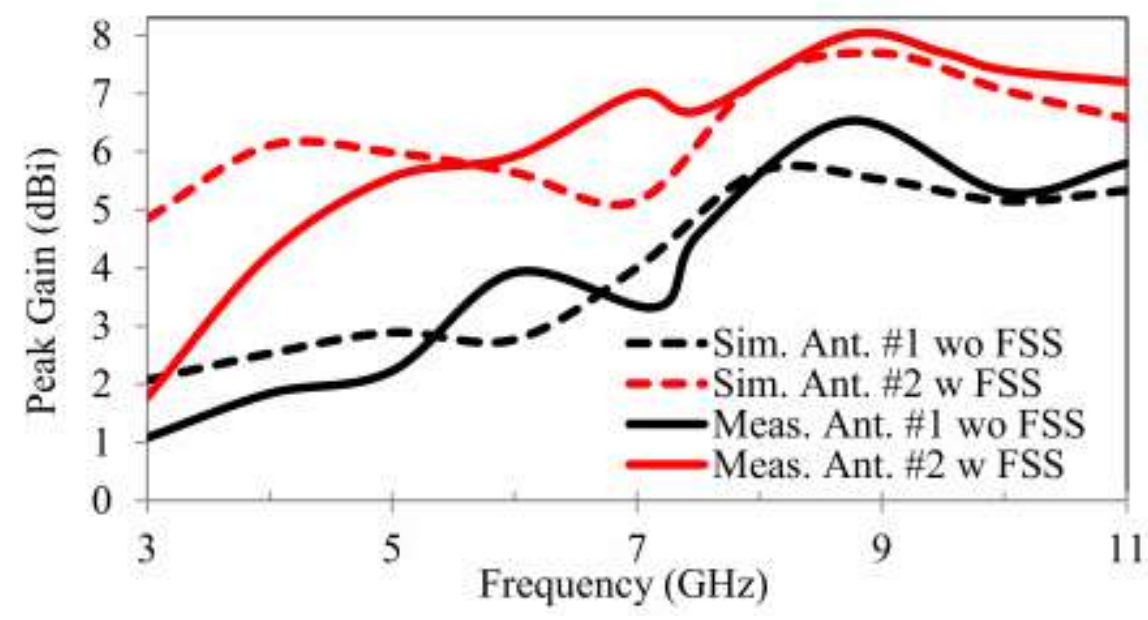

FIGURE 11 The measurement and simulation gain results of Antenna \#1 and Antenna \#2 
- Sim. Ant $\# I$ wo FSS xz plane (Phi $\left.=0^{\circ}\right) 4 \mathrm{GHz}$ $\rightarrow$ Meas. Ant $\# 1$ wo FSS xz plane $\left(\mathrm{Phi}^{\circ}=0^{\circ}\right) 4 \mathrm{GHz}$ - - Sim. Ant $\| 1$ wo FSS yz plane (Phi=90\%) $4 \mathrm{GHz}$

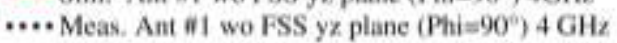

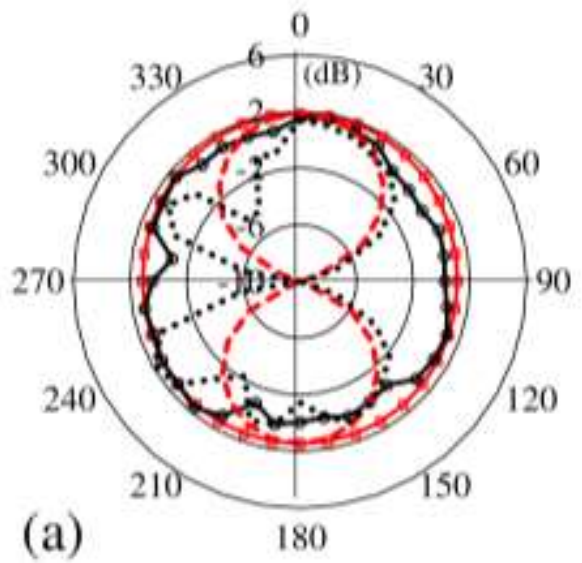

-6-Sim. Ant $\# 1$ wo FSS $x z$ plane $(\mathrm{Phi}=0$ ) $5 \mathrm{GH} z$ $\rightarrow$ Meas, Ant $\# I$ wo FSS xz plane (Phim $\left.0^{\circ}\right) 5 \mathrm{GHz}$ - - Sim. Ant $\| 1$ wo FSS yz plane (Phi $\left.=90^{\circ}\right) 5 \mathrm{GHz}$ .... Meas, Ant $\# 1$ wo FSS yz plane (Phim90\%) $5 \mathrm{GH}$,

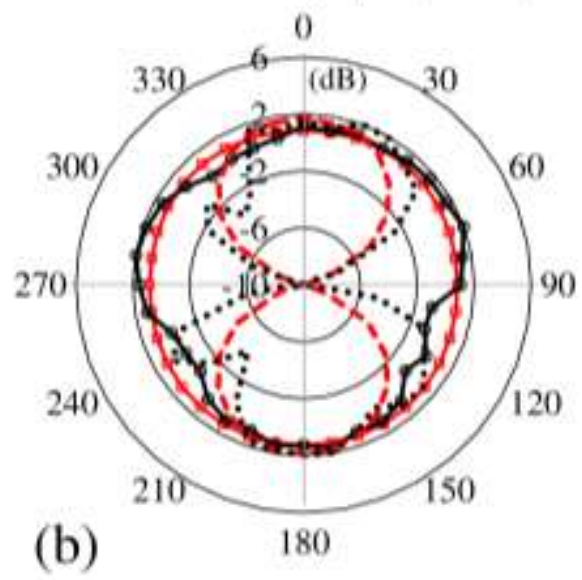

- Sim. Ant $\# 1$ wo FSS xz plane $\left(P h i=0^{\circ}\right) 6 \mathrm{GHz}$ - Meas. Ant 01 wo PSS xz plane $\left(\right.$ Phi $\left.=0^{\circ}\right) 6 \mathrm{GH}$ - - Sim. Ant $\# 1$ wo FSS yz plane $\left(\mathrm{Phi}=90^{\circ}\right) 6 \mathrm{GHz}$ ... Meas. Ant il wo FSS yz plane (Phi $\left.=90^{\prime \prime}\right) 6 \mathrm{GH}$,

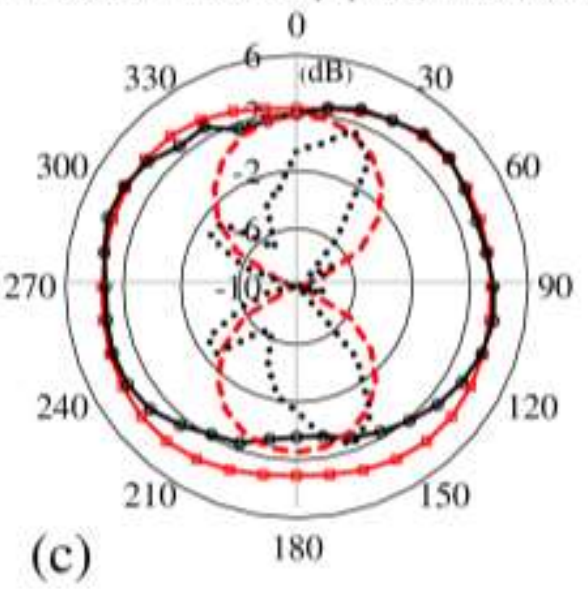
- Sim. Ant 12 w FSS xz plane $\left(P h i m 0^{\circ}\right) 4 G H z$
- Meas. Ant 12 w FSS $x z$ plane $\left(P h i=0^{\circ}\right) 4 G H z$
- Sim. Ant 12 w FSS yz plane (Phi $\left.=90^{\circ}\right) 4 G H z$
$\ldots$ Meas. Ant 12 w FSS yz plane $\left(P h i=90^{\circ}\right) 4 G H z$

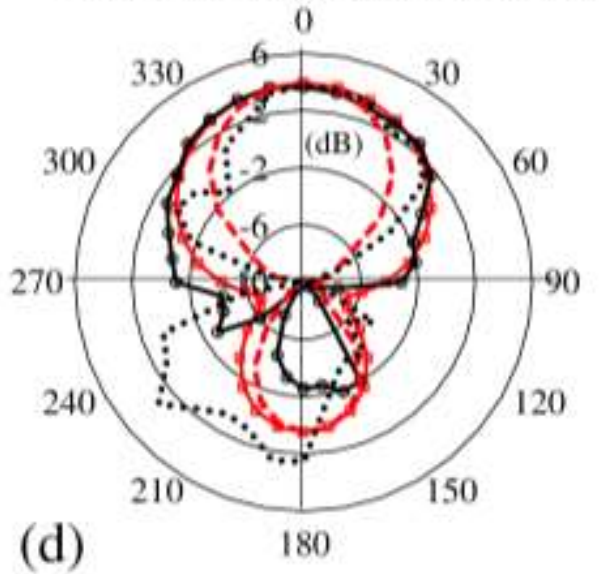

- Sim. Ant 12 w FSS xz plane (Phim $0^{\circ}$ ) $5 \mathrm{GHz}$ $\rightarrow$ Meas, Ant 12 w FSS $x z$ plane $\left(P h i=0^{\circ}\right) 5 G H z$ - - Sim. Ant 12 w FSS yz plane $\left(\mathrm{Phi}=900^{\circ}\right) 5 \mathrm{GHz}$ $\cdots$ Meas. Ant $\# 2$ w FSS yz plane $\left(\mathrm{Phi}=90^{\circ}\right) 5 \mathrm{GHz}$

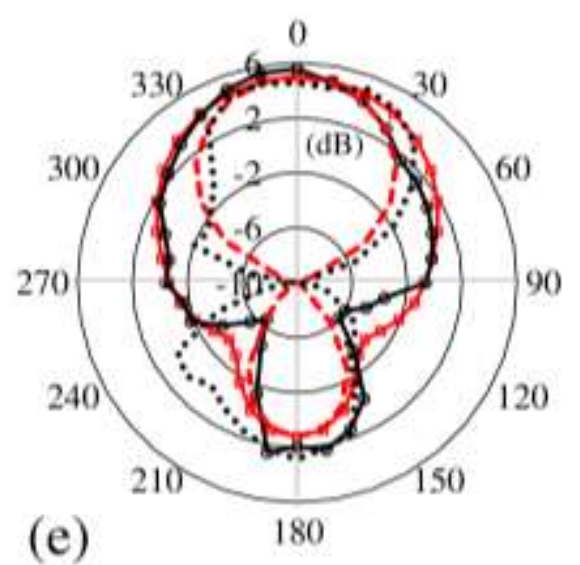

- $-\operatorname{Sim}$. Ant $\# 2$ w FSS $x z$ plane $\left(P h i=0^{\circ}\right) 6 \mathrm{GHz}^{\circ}$ - Meas. Ant $\# 2$ w FSS xz plane (Phi $\left.=0^{\circ}\right) 6 \mathrm{GHz}$

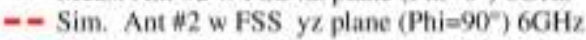
.... Meas. Ant 42 w FSS yz plane (Phim $\left.90^{\circ}\right) 6 \mathrm{GHz}$

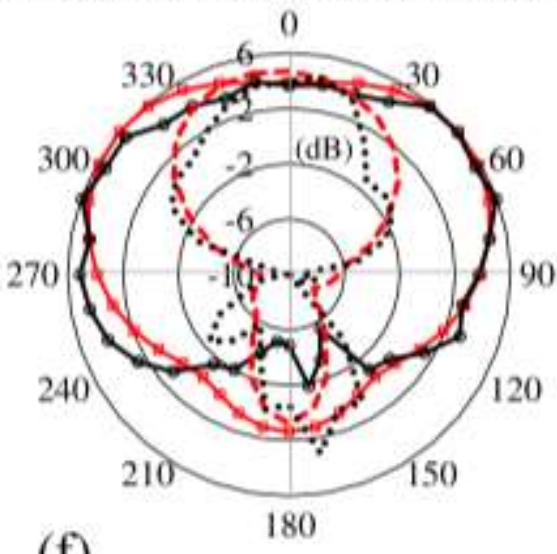

(f)

FIGURE 12 The simulation in comparison to measurements radiation patterns of Antenna \#1 in (a, b, and c) and Antenna \#2 in (d, e, and f) at 4, 5, and $6 \mathrm{GHz}$ 
After that, the measured and simulated radiation patterns of Antennas \#1 and \#2 were compared, as shown in Figure 12. The outcomes are presented in both E-plane (yz plane) and $\mathrm{H}$-plane (xz plane) at 4, 5, and $6 \mathrm{GHz}$ frequencies. Typically, the hexagonal patch of Antenna \#1 generated the omnidirectional radiation pattern of H-plane, whereas the UDRs of H- and E-planes were attained at the tested frequencies of Antenna \#2 with FSS array. The $3 \mathrm{~dB}$ angular beam width H-plane of Antenna \#2 was directed to Theta angles of $0^{\circ}, 0^{\circ}$, and $30^{\circ}$ at 4, 5, and $6 \mathrm{GHz}$, respectively. The radiation pattern exhibited good agreement between the simulation and measurement outcomes. A further narrow beam width was noted by increasing the FSS array elements, which also increased the design size. In precise, the proposed low-cost single-layer compact FSS successfully reflected the monopole antenna radiation patterns over the broad bandwidth.

\section{5 | MWI MODEL AND RESULTS}

To verify the ability of the suggested antenna for MWI applications, several metallic objects were hidden inside a simulated handbag model by using the CST Microwave Studio as a case study. In the MWI approach, the scattering data must be recorded at multiple points along the test area (scanning plane) to attain high resolution. The simulated handbag model with scanning scheme is shown in Figure 13a by using the proposed antenna. The bag was made of a textile material with dielectric constant approximately $\varepsilon_{r}=1.85$ [27] and a 3D size of $110 \times 140 \times 70 \mathrm{~mm}^{3}$. Three metallic strips were formed in rectangular shape and size $10 \times$ $20 \times 10 \mathrm{~mm}^{3}$. After that, the strips were set vertically and horizontally at various locations in the modeled handbag.

In this study, the monostatic approach was applied by using a 2D linear scanning method. The proposed antenna was pointed at a distance $R d$ of $110 \mathrm{~mm}$ from the tested model for short distance detection with complete operating bandwidth. Figure 13b shows that the transmuted Gaussian pulse signal was generated as a default input signal of the software. The design was simulated with a carrier frequency at bandwidth ranging between 3 and $14 \mathrm{GHz}$. During the linear scanning, the transmitted signals were reflected from the bag model and recorded based on the monostatic approach at a particular time. The outputs that reflected signals within the time domain were recorded from the simulation at 121 points along with the area of $110 \times 110 \mathrm{~mm}^{2}$ of the model. This scheme portrayed a step-shift ) $\Delta \mathrm{x}$ and $\Delta \mathrm{y}$ ) of $10 \mathrm{~mm}$ between every two adjacent scanned points. 


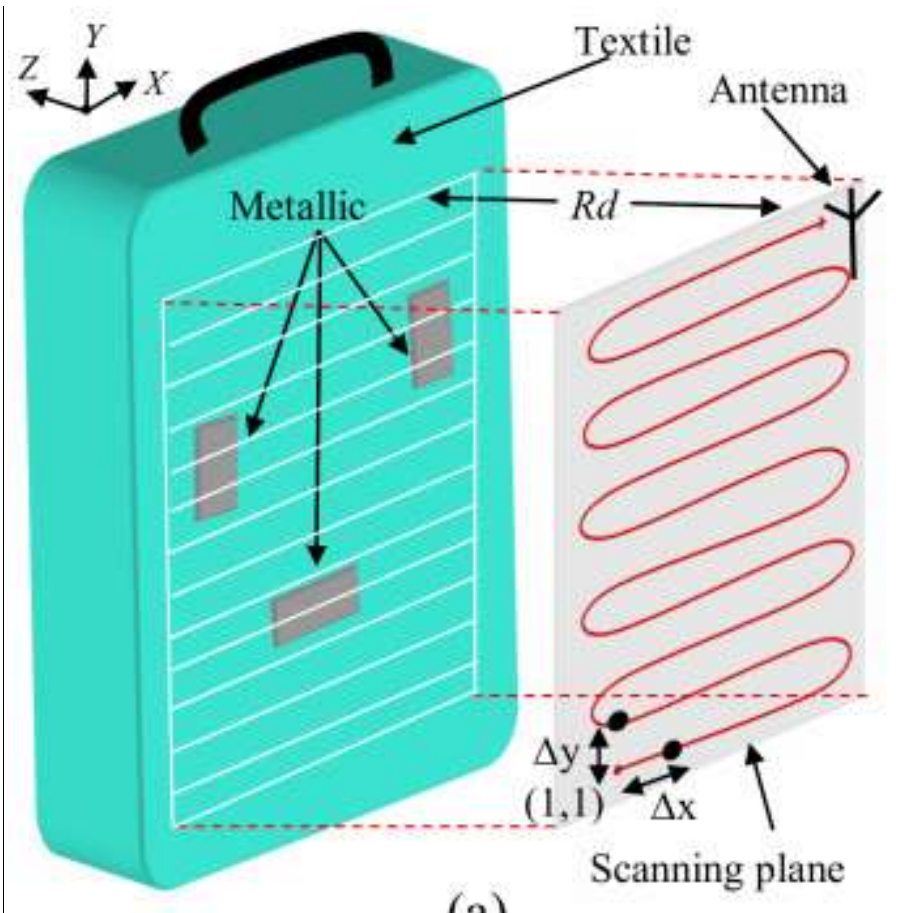

(a)

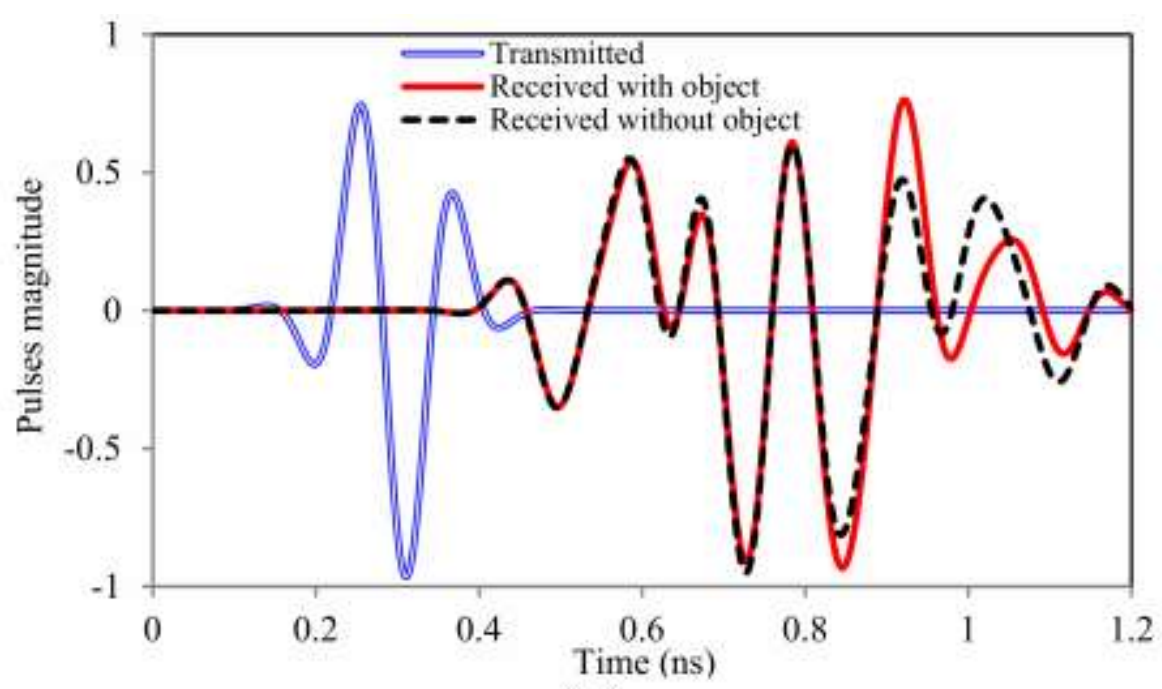

(b)

FIGURE 13 (a) 3D view of the handbag model and scanning scheme, (b) normalized transmitted and received signals

The normalized received signals within the time domain were analyzed by using MATLAB. The received signals of 121 scanned iterations were recorded into two matrices. In the first matrix, the $\mathrm{y}$-axis presented the scanned iterations at varied locations, while the $\mathrm{x}$ axis received the time (nanosecond $[\mathrm{ns}]$ ). In the second matrix, the $\mathrm{x}$-axis represented normalized received signal magnitude with similar indices of the time matrix. The magnitudes of the received signals fluctuated at $0.92 \mathrm{~ns}$, as displayed in Figure $13 \mathrm{~b}$.The 
recorded time represented the distance from the antenna using propagation rates in various media. The data were mapped to the image matrix for further imaging process.

Next, the data were compared to determine the time $(0.92 \mathrm{~ns})$ that produced the highest varied peaks. The maximum different packs were recorded in the new image matrix of the 121 scanned locations. A2 D image was plotted in(x, y) coordinates. For imagingevaluation, the proposed imaging process was implemented twice of Antenna \#1 without FSS and Antenna \#2 with FSS. Figure 14 illustrates the scanned images of the simulated model within the time domain. The 2D image in Figure 14a clearly shows that the metallic objects were visible at the exact spots based on enhanced Antenna \#2. Nonetheless, Antenna \#1 without FSS gave a low resolution image in Figure 14b due to low antenna gain. The dark red area within the time domain output presented higher reflection magnitudes. In precise, the proposed design is suitable for MWI applications.

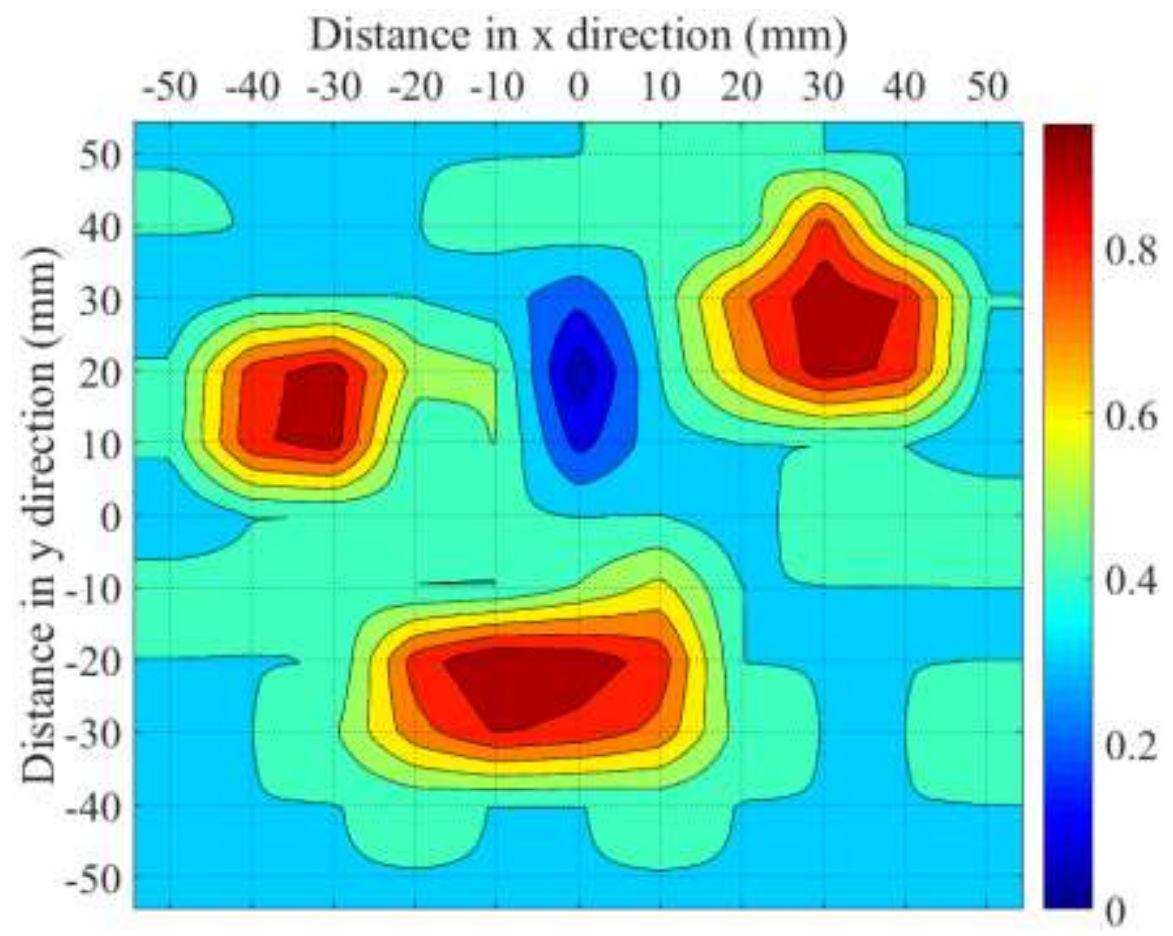

(a) 


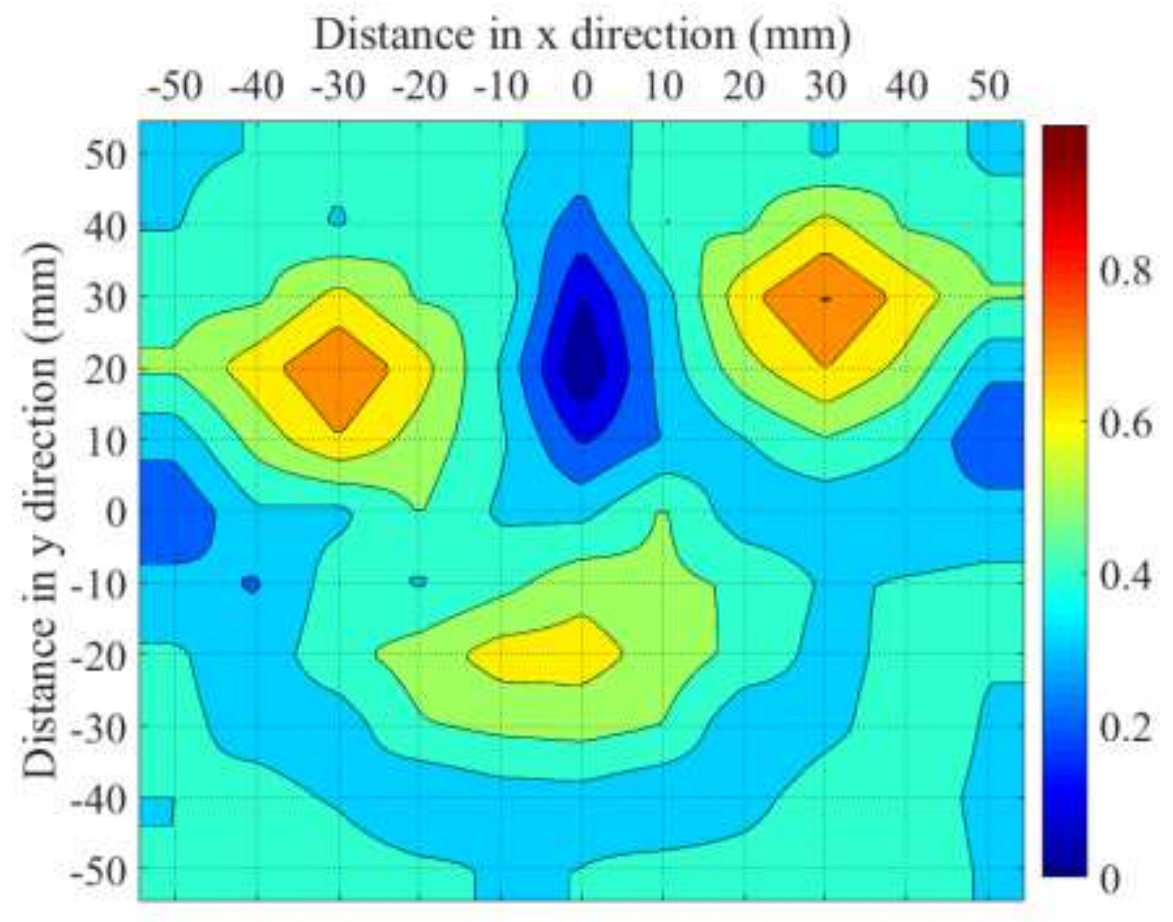

(b)

FIGURE 14 2D images of the scanned model by using Antenna \#2 with FSS in )a (and

\section{Antenna \#1 without FSS in(b)}

The image presents three objects(red) with high resolution, in comparison to the background(blue). High accuracy of $\pm 5 \mathrm{~mm}$ recorded the location of the objects due to antenna sizeand scanning step-shift $(10 \mathrm{~mm})$. However, more processes were required to display the exact shape and features of the objects. The image also showed the size of the objects; $15 \times 15 \mathrm{~mm}^{2}, 20 \times 20 \mathrm{~mm}^{2}$, and $15 \times 25 \mathrm{~mm}^{2}$. The proposed scheme obtained a scanning image by using low-complexity signal-processing and low- cost microwave detection approach by considering image resolution. The monostatic approach propagated the signals in the UWB bandwidth. The proposed antenna detected the scattered signals, in which three objects were vividly detected, as displayed in Figure 14a.

Practically, the monostatic systems perform the same antenna for both transmitting and receiving signals, respectively. The antenna in the UWB detection system first transmits a pulse within a short time period, and then thesystem switches the mode and starts receiving scattered signal for another time period. The received signal is reflected from the echoes of the transmitted energy that are scattered from thetarget. The received signal represents the RF energy of the scattered signal due to the target size and material, while the travelling time through the media represents the distance, $R d$, between the target and the antenna. This 
system is usually much cheaper than the bi- static system because it requires fewerantennas and RF cables, but it is utilized for short distance detection applications.

The design of Antenna \#2 was $30 \times 31.9 \times 21.6 \mathrm{~mm}^{3}$ size. In this study, both UWB antenna and FSS unit cell were miniaturized. FSS size, bandwidth, layers, and reflection phase in the literature were compared with the proposed FSS, as tabulated in Table 2. The proposed system was smaller in size, generated high gain, gave UDRs, and cost-effective for manufacturing. Therefore, the proposed design is indeed suitable for MWI applications.

TABLE 2. Parametric comparison of the literature that used FR4 substrate

\begin{tabular}{|l|l|l|l|l|}
\hline References & Unit cell size & $\begin{array}{l}\text { Stop bandwidth } \\
(\mathrm{GHz}) \mathrm{S}_{21}<-10 \mathrm{~dB}\end{array}$ & $\begin{array}{l}\text { Reflection } \\
\text { phase }\left(\mathrm{S}_{11}\right)\end{array}$ & $\begin{array}{l}\text { Number of } \\
\text { FSS planes }\end{array}$ \\
\hline$[16]$ & $0.22 \lambda \times 0.22 \lambda$ & $4-12$ & Nonlinear & Two \\
\hline$[18]$ & $0.188 \lambda \times 0.188 \lambda$ & $3.9-11.1$ & Linear & Two \\
\hline$[6]$ & $0.158 \lambda \times 0.158 \lambda$ & $3.4-12.9$ & Linear & Two \\
\hline$[20]$ & $0.153 \lambda \times 0.153 \lambda$ & $4.6-16$ & - & Two \\
\hline$[14]$ and $[15]$ & $0.146 \lambda \times 0.146 \lambda$ & $4-7$ & Nonlinear & Two \\
\hline$[19]$ & $0.14 \lambda \times 0.14 \lambda$ & $3-12$ & Linear & Two \\
\hline$[7]$ & $0.135 \lambda \times 0.135 \lambda$ & $2.7-13.2$ & - & Four \\
\hline$[17]$ & $0.108 \lambda \times 0.108 \lambda$ & $3-15$ & Nonlinear & Two \\
\hline Proposed & $0.095 \lambda \times 0.095 \lambda$ & $2.6-11.1$ & Linear & One \\
\hline
\end{tabular}

\section{6 | CONCLUSION}

In this article, the gain enhancement of UWB monopole antenna CPW-fed based on compact uniplanar FSS array for MWI application was explored. For that purpose, this study built a single-layer small-size FSS unit cell based on copper cross-dipole and square-ring on FR4 substrate as UWB reflector. The miniaturized FSS unit cell size of $0.095 \lambda \times 0.095 \lambda$ experimentally observed low transition coefficient of $-49 \mathrm{~dB}$, broad bandwidth of 2.6 to 11.1 $\mathrm{GHz}$, and linear phase reflection, which had been in line with the outcomes of both the simulated equivalent circuit and the measured $54 \times 36$ FSS array prototype. Next, the fabricated hexagonal patch monopole UWB antenna CPW-fed with FSS array realized the broad bandwidth from 3.8 to $10.6 \mathrm{GHz}$. At an optimum air-gap of $21.6 \mathrm{~mm}$, the gain of UWB antenna was enhanced by about $3.5 \mathrm{dBi}$ with the application of $3 \times 3$ FSS array. In the experiment, the characteristics of the proposed antenna were evaluated in two cases; with and without FSS. The UWB monopole antenna with FSS generated UDRs patterns. A good 
agreement was observed between the measured and the simulated characteristics. Subsequently, the proposed antennas with and without FSS array were used to scan a new simulated handbag model using CST, which detected metallic objects based on the MWI baggage scanner system. The antenna with FSS displayed image with higher resolution, when compared to that exhibited by antenna without FSS via MATLAB. The developed lowcomplexity imaging system gave high accuracy of $\pm 5 \mathrm{~mm}$ location for the three small $(1 \times 2$ $\mathrm{cm}^{2}$ ) objects due to the high performance of the developed antenna for practical verification. Forthcoming, experimental preparation to scan a conventional handbag is considered for practical imaging evaluation. In summary, miniaturizing the size and maximizing the gain of the proposed design gave excellent resolution of the MWI system. Although the UWB monopole antenna with miniaturized FSS was small in size, it successfully offered higher gain, broader bandwidth, better UDRs, easy-to-setup, and cost-effective, hence a potential candidate for early detection of concealed objects in passenger luggage security application.

\section{ACKNOWLEDGEMENT}

The authors are thankful to Universiti Tun Hussein Onn Malaysia for sponsoring this work and would like to display gratitude to all staff members of EMC, WARAS, PCB, RF, and RACAD labs for providing the simulation, the fabrication, and the measurement facilities.

\section{REFERENCES}

[1] Gibbins D, Klemm M, Craddock IJ, Leendertz JA, Preece A, Benjamin R. A comparison of a wide-slot and a stacked patch antenna for the purpose of breast cancer detection. IEEE transactions on antennas and propagation. 2010;58(3):665-74.

[2] Edalati A, Shao W, McCollough T, McCollough W. A Novel Cavity Backed Monopole Antenna with UWB Unidirectional Radiation. Progress In Electromagnetics Research. 2017;72:1-13.

[3] Mobashsher AT, Abbosh A. Performance of directional and omnidirectional antennas in wideband head imaging. IEEE Antennas and Wireless Propagation Letters. 2016; $15: 1618-21$.

[4] Latif S, Flores-Tapia D, Pistorius S, Shafai L. A planar ultrawideband elliptical monopole antenna with reflector for breast microwave imaging. Microwave and Optical Technology Letters. 2014;56(4):808-13.

[5] Mobashsher AT, Abbosh A. Development of compact directional antenna utilising plane of symmetry for wideband brain stroke detection systems. Electronics Letters. 2014;50(12):850-1.

[6] Kushwaha N, Kumar R, Oli T. Design of a high-gain ultra-wideband slot antenna using frequency selective surface. Microwave and Optical Technology Letters. 2014;56(6):1498-502. 
[7] Ranga Y, Matekovits L, Weily AR, Esselle KP. A constant gain ultra-wideband antenna with a multi-layer frequency selective surface. Progress In Electromagnetics Research. 2013;38:119-25.

[8] Paracha KN, Abdul Rahim SK, Soh P, Chatha HT, Misran MH, Lokman AH. A dual band stub-loaded AMC design for the gain enhancement of a planar monopole antenna. Microwave and Optical Technology Letters. 2018;60(9):2108-12.

[9] Liu Y, Hao Y, Gong S. Low-profile high-gain slot antenna with Fabry-Pérot cavity and mushroom-like electromagnetic band gap structures. Electronics Letters. 2015;51(4):305-6.

[10] Elwi TA. A miniaturized folded antenna array for MIMO applications. Wireless Personal Communications. 2018;98(2):1871-83.

[11] Elwi TA, Al-Rizzo HM, Rucker DG, Song F. Numerical simulation of a UC-PBG lens for gain enhancement of microstrip antennas. International Journal of $R F$ and Microwave Computer-Aided Engineering. 2009;19(6):676-84.

[12] Peddakrishna S, Khan T, Kanaujia BK. Resonant characteristics of aperture type FSS and its application in directivity improvement of microstrip antenna. AEU-International Journal of Electronics and Communications. 2017;79:199-206.

[13] Peddakrishna S, Khan T. Performance improvement of slotted elliptical patch antenna using FSS superstrate. International Journal of RF and Microwave Computer-Aided Engineering. 2018:e21421.

[14] Chatterjee A, Parui SK. A dual layer frequency selective surface reflector for wideband applications. Radioengineering. 2016;25(1):67-72.

[15] Chatterjee A, Parui SK. Gain enhancement of a wide-slot antenna using dual-layer, bandstop frequency selective surface as a substrate. Microwave and Optical Technology Letters. 2015;57(9):2016-20.

[16] Ranga Y, Matekovits L, Esselle KP, Weily AR. Multioctave frequency selective surface reflector for ultrawideband antennas. IEEE Antennas and Wireless Propagation Letters. 2011;10:219-22.

[17] Kundu S, Chatterjee A, Jana SK, Parui SK. Gain enhancement of a printed leaf shaped UWB antenna using dual FSS layers and experimental study for ground coupling GPR applications. Microwave and Optical Technology Letters. 2018;60(6):1417-23.

[18] Krishna RR, Kumar R, Kushwaha N. A Circularly Polarized Slot Antenna for High Gain Applications. AEU-International Journal of Electronics and Communications. 2014;68(11):1119-28.

[19] Tahir FA, Arshad T, Ullah S, Flint JA. A novel FSS for gain enhancement of printed antennas in UWB frequency spectrum. Microwave and Optical Technology Letters. 2017;59(10):2698-704.

[20] Majidzadeh M, Ghobadi C, Nourinia J. Novel single layer reconfigurable frequency selective surface with UWB and multi-band modes of operation. AEU-International Journal of Electronics and Communications. 2016;70(2):151-61.

[21] Munk BA. Frequency selective surfaces: theory and design. 1st ed. New York, USA: John Wiley \& Sons, Inc; 2000.

[22] Pozar DM. Microwave Engineering. 4th ed. New York, USA: John Wiley \& Sons; 2012.

[23] Grover FW. Inductance Calculations. New York, USA: Dover Publications; 2013.

[24] Abdulhasan RA, Alias R, Ramli KN. A Compact CPW Fed UWB Antenna with Quad Band Notch Characteristics for ISM Band Applications. Progress In Electromagnetics Research. 2017;62:79-88.

[25] Ray K. Design aspects of printed monopole antennas for ultra-wide band applications. International Journal of Antennas and Propagation. 2008;2008(713858):1-8. 
[26] Seman FC, Cahill R, Fusco V, Goussetis G. Design of a Salisbury screen absorber using frequency selective surfaces to improve bandwidth and angular stability performance. IET microwaves, antennas \& propagation. 2011;5(2):149-56.

[27] Hertleer C, Rogier H, Vallozzi L, Van Langenhove L. A textile antenna for off-body communication integrated into protective clothing for firefighters. IEEE Transactions on Antennas and Propagation. 2009;57(4):919-25.

\section{AUTHOR BIOGRAPHIES}

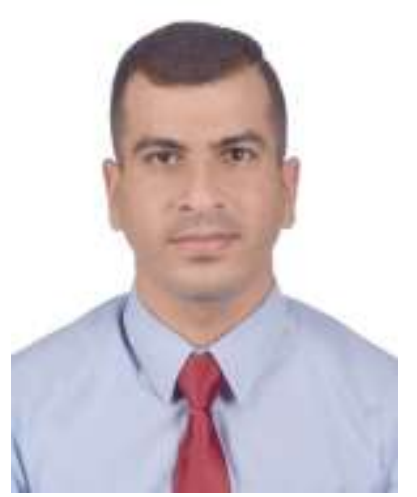

RAED ABDULKAREEM ABDULHASAN was born in Baghdad, Iraq. He received the BEng degree in Electrical Engineering from AL-Mustansiriya University, Baghdad, Iraq, in 2006, and then MEng (with honors) in Communications Engineering from Faculty of Electrical and Electronic Engineering, University Tun Hussein Onn Malaysia (UTHM), Malaysia, in 2015. He is currently finalizing the $\mathrm{PhD}$ degree at Faculty of Electrical and Electronic Engineering, University Tun Hussein Onn Malaysia. He received several awards and a number of medals in international and local competitions. He has published more than 20 academic journal and conference papers. He is currently a member and refereed of the Institution of Engineering and Technology (IET). His research interests include antenna design and miniaturization, frequency selective surface (FSS), EBG, AMC, MTM, Microwave imaging/detection, radar, interference reduction, wireless and mobile communications, Artificial Intelligence, and optimizations.

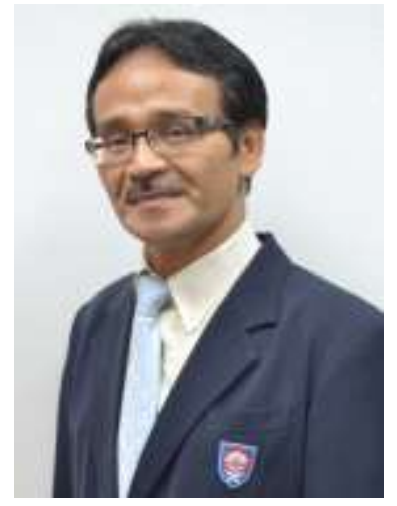

ROZLAN ALIAS was born in Tanjong Malim, Perak, Malaysia in 1965. He received a BEng degree (with honors) in Electrical Engineering from the University of Malaya, Kuala Lumpur in 1991, a MSc degree in Digital Communication Systems from the University of Loughborough, UK in 1998, and a Ph.D. degree in Electronics and Telecommunication from the University of Bradford, UK in 2006. He held the lecturing position at Universiti Kuala Lumpur (UniKL BMI), Gombak, Selangor for several years. He is currently a Senior Lecturer at the Universiti Tun Hussein Onn Malaysia (UTHM), Parit Raja, Batu Pahat, Johor, Malaysia. His research interests cover the hybrid electromagnetic computational techniques, antenna design and low SAR antennas for mobile handset. 


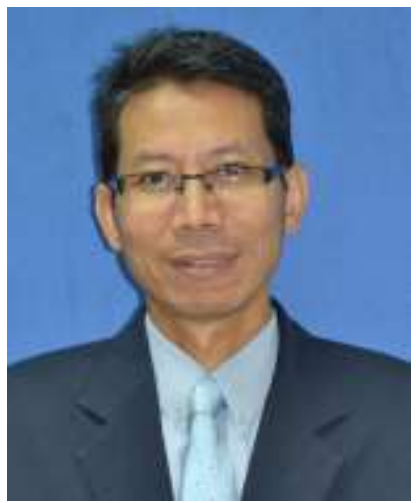

KHAIRUN NIDZAM RAMLI was born in Batu Pahat, Johor, Malaysia, in 1974. He obtained a BEng degree in Electronic Engineering from the University of Manchester Institute of Science and Technology (UMIST), UK, in 1997, and then MEng in Universiti Kebangsaan Malaysia (UKM), Malaysia in 2004. Then from 2007 he worked within Antennas and Applied Electromagnetic research group at University of Bradford, UK. He received a Ph.D. degree for research in electromagnetic problems using hybrid computational methods from the University of Bradford, UK in 2011. He is currently working at the Faculty of Electrical and Electronic Engineering, Universiti Tun Hussein Onn Malaysia (UTHM). His main interests are in the field of computational electromagnetics, antennas, and wireless communications. He is a graduate member of Board Engineers Malaysia (BEM), member of the Institute of Electrical and Electronics Engineers (IEEE), and member of Jalur Selatan Radio Amatur (JASRA) Johor, Malaysia.

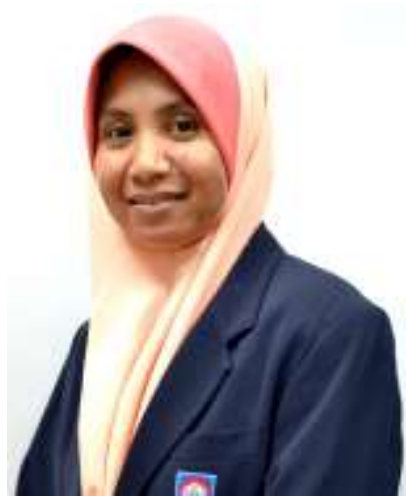

FAUZIAHANIM CHE SEMAN (M'14) received the degree in electrical communication engineering from Universiti Teknologi Malaysia in 2001, the master's degree from Universiti Tun Hussein Onn Malaysia in 2003, and the Ph.D. degree from the Queen's University of Belfast, U.K., in 2011. After the Master's degree, she joined the Faculty of Electrical Engineering, Universiti Tun Hussein Onn Malaysia as a Lecturer, where she is currently an Associate Professor and senior researcher Research Center of Applied Electromagnetic. She has published number of index journals and conference proceedings and taken various patents. Her research interests include radar microwave absorber, frequency selective surface, antenna design, and copper access networks. She actively become the IEEE volunteers since 2014, as executive committee, secretary and recently chapter chair of IEEE Malaysia AP/MTT/EMC Joint Chapter. She involved in the organizing committee for various IEEE conferences. 


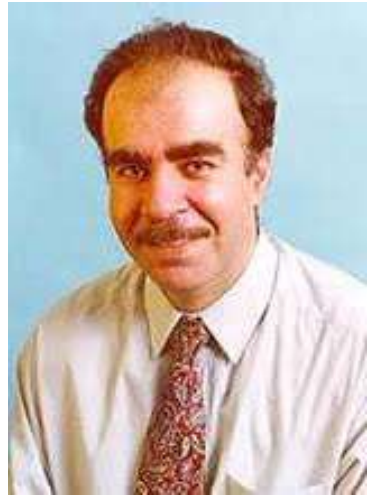

RAED A. ABD-ALHAMEED (M'02-SM'13) received the B.Sc. and M.Sc. degrees in electrical engineering from Basrah University, Basrah, Iraq, in 1982 and 1985, respectively, and the Ph.D. degree in electrical engineering from the University of Bradford, U.K., in 1997. He has also been a Research Visitor with Glyndwr University, Wrexham, U.K., since 2009. He is currently a Professor of electromagnetic and radio frequency engineering with the University of Bradford. He is the Leader of radio frequency, propagation, sensor design, and signal processing. He leads the Communications Research Group, School of Engineering and Informatics, Bradford University, for years. He is investigator of several funded applications. He has published more than 500 academic journal and conference papers, and books. His research interests include computational methods and optimizations, wireless and mobile communications, sensor design, signal processing, EMC, propagations, antennas, beam steering, energy-efficient PAs, and RF predistorter design applications. 